\title{
Spatiotemporal Control of the Creation and Immolation of Peptide Assemblies
}

\author{
Yang $\mathrm{Hu},{ }^{\dagger, \ldots,}$ Ran Lin, ${ }^{\ddagger, \S}$ Kunal Patel, ${ }^{\|}$Andrew G. Cheetham, ${ }^{\ddagger, \S}$ Chengyou Kan, ${ }^{\dagger}$ Honggang Cui ${ }^{*, \hbar,, \nabla}$ \\ ${ }^{\dagger}$ Department of Chemical Engineering, Tsinghua University, Beijing, 10084, China; ${ }^{*}$ Department of \\ Chemical and Biomolecular Engineering, Johns Hopkins University, Baltimore, Maryland 21218; ${ }^{\S}$ Institute \\ for NanoBiotechnology (INBT), Johns Hopkins University, Baltimore, Maryland 21218, United States; \\ "Department of Biomedical Engineering, Johns Hopkins University, Baltimore, Maryland 21218, United \\ States; ${ }^{\nabla}$ Department of Oncology and Sidney Kimmel Comprehensive Cancer Center, Johns Hopkins \\ University School of Medicine, Baltimore, Maryland 21205, USA.
}

Abstract: Peptides are excellent building units to construct supramolecular biomaterials for diverse biomedical applications. A vast amount of research effort over the past two decades has focused on the rational design of peptidic building units and the formulation protocols required to create supramolecular assemblies that can chemically and structurally emulate the functions of naturally occurring nanostructures. A rapidly growing interest in the field is the spatiotemporal regulation of the formation and immolation pathways of peptide assemblies, an essential characteristic to control if these constructs are to fulfil their roles as biologically active and compatible materials. In this review, we discuss the necessity for control over the assembly and morphological transformation of peptides and peptide conjugates, the critical role of these properties for their ultimate biological application, as well as the methods by which this can be programmed into the molecular structure. A particular focus will be on recent advances in the use of enzyme and redox process for exerting spatiotemporal control over a variety of peptide-based nanostructures.

Keywords:

Spatiotemporal control; peptide assemblies; biomaterials; immolative materials; molecular assembly.

\section{Content}

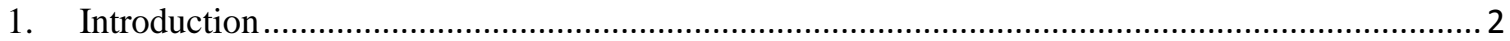

2. Principles of Controlled Peptide Assembly ...................................................................... 3

3. Peptide and Peptide Derivatives..................................................................................... 4

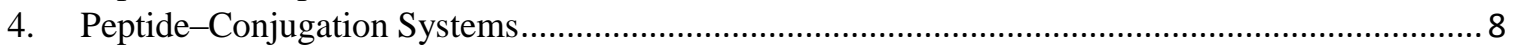

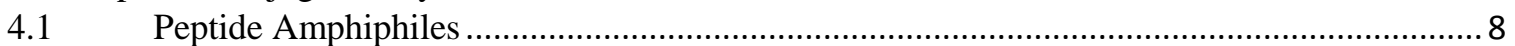

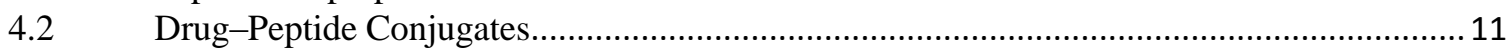

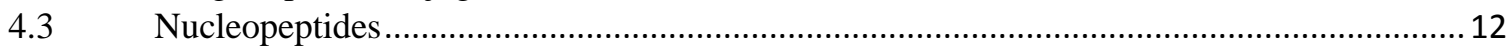

Metal Complex-Peptide Conjugates ........................................................................ 13

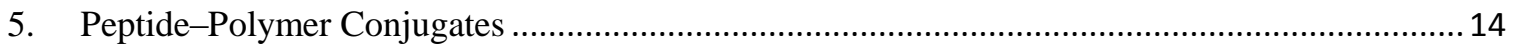

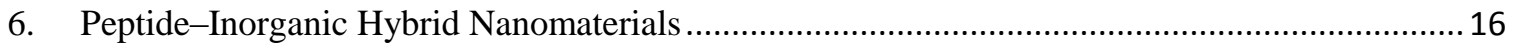

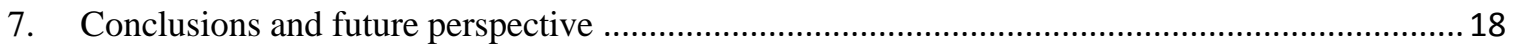

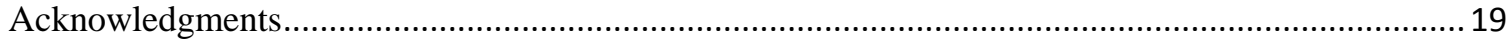

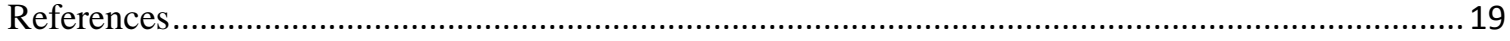




\section{Introduction}

Peptides are relatively short sequences of amino acids and can perform a wide range of biological functions to mediate many intercellular, cellular, and subcellular activities. As structural units, they are able to assemble into a variety of supramolecular nanostructures that expand their functional space for use as biomaterials [1-11]. Extensive efforts in peptide research over the past two decades have led to the development of peptidic biomaterials with precisely tailored mechanical, biological, and structural properties $[5,6,8,12]$. However, for any specific biomedical setting, it has been increasingly recognized that not only the well-tailored, initial properties but also the materials' adaptability (the change of properties with time and in response to biology) as well as their immolation pathways, are equally essential to achieve the desired biological/biomedical functions. For example, in the design of biomaterials to assist in wound healing, it is crucial to tailor their mechanical properties and payload release rates to deliver cells and growth factors to accelerate the wound healing process. After the delivery function is fulfilled, it is hoped that these materials will break down in a timely manner for effective clearance and also to make room for the growth of new tissues. Similarly in the context of drug delivery, the nanostructure carrier should be able to hold its size and shape during circulation for a robust and predictable pharmacokinetic profile, but upon arriving at the target site it should rapidly disassociate to release its payload, enabling a specific treatment of pathogenic cells [10]. Indeed, the formation and immolation of many structural units in living organisms are highly regulated biologic events that take place only in a particular period of time and at a particular site. Dysregulated formation and immolation of protein aggregates could lead to function disorders. For example, the deposition of amyloid $\beta$-peptide $(\mathrm{A} \beta)$ plaques in the brain are implicated in neurodegenerative diseases such as Alzheimer's and Parkinson's, and this abnormal amyloid aggregation results from an imbalance between $\mathrm{A} \beta$ production and clearance [13-15]. Therefore, from the perspectives of both biomedical applications and bioinspired materials design, spatiotemporal control has become an increasingly important guiding principle for the development of peptidic biomaterials to specifically interface with biology.

To spatiotemporally control the creation and immolation of peptide assemblies, the principle of design is to create molecular building blocks that can be specifically responsive to changes in environmental factors, such as $\mathrm{pH}$, ionic strength, temperature, light, ultrasound, redox state, and/or enzymatic activities [16-25] Among all these factors, $\mathrm{pH}$, ionic strength, redox state, and enzyme catalysis are the four most common bio-factors dispersed widely and uniquely in living systems. First of all, body fluid or interstitial fluid surrounding cells contains proteins, electrolytes, fatty acids, and a myriad of other types of bioactive molecules, and its high ionic strength could screen electrostatic interactions of charged peptides so as to induce their self-assembly into supramolecular nanostructures. Second, $\mathrm{pH}$ difference in various subcellular compartments such as lysosomes can be used to trigger release of payload from $\mathrm{pH}$-sensitive carriers. Also, the lower $\mathrm{pH}$ value of the extracellular environment of tumorous tissues ( 6.8 vs. 7.4), as a result of hypoxia-induced glycolysis that increases lactate production, can be exploited to design cancer therapeutics and diagnostics for controlled release. Third, enzymes are an important class of biological triggers for many important reactions. Tumor progression and invasion are often accompanied by the abnormal activities of various enzymes, and in some cases these tumor-relevant enzymes show a difference in intracellular and extracellular distribution, thus serving as a potential biochemical trigger for both peptide aggregation and immolation. Lastly, some disease-related reductive/oxidative agents represent another group of potential stimuli to regulate peptide assembly. For example, glutathione (GSH) is an important antioxidant to prevent harms caused by reactive oxygen species such as free radicals, peroxides, and heavy metals. In tumorous tissues, the intracellular GSH levels were found to be up to ten times higher than that in normal cells, providing the cancer cells with protection against oxidation and cytotoxic compounds.

In this context, we will describe recent progress in the programmed assembly of peptides and peptide conjugates, as well as the specific immolation of their supramolecular nanostructures. Since peptide materials responding to $\mathrm{pH}$ and ionic strength have been systematically reviewed elsewhere [19, 26-28], we highlight the strategies for using enzymatic activities and redox processes to achieve spatiotemporal control of peptide-based assembly (Figure 1). It is not our intention to provide a comprehensive review of the field, but rather, we will focus on several representative examples to illustrate the importance of the spatiotemporal control of peptide assembly and immolation. 


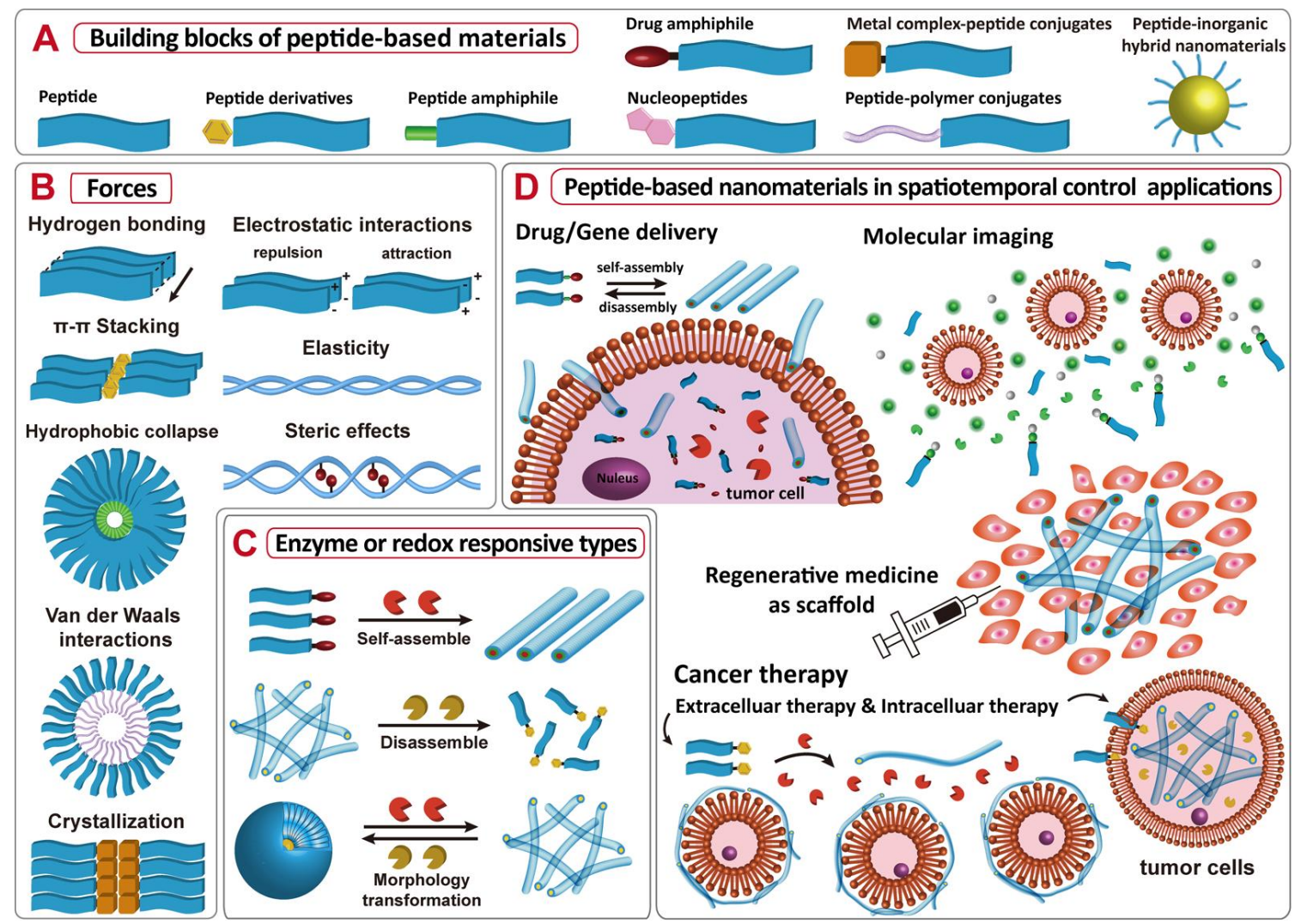

Fig. 1. Overview of the peptidic building blocks and the spatiotemporal control of their assembly, disassembly, and immolation for various biomedical applications. (A) Illustration of the peptide-based materials. (B) Forces that govern the self-assembled peptide nanostructures. (C) The role of enzymes and redox reactions in nanostructure control. (D) Peptide-based nanomaterials in spatiotemporal control applications.

\section{Principles of Controlled Peptide Assembly}

Appropriately designed peptides and their derivatives possess the capacity for self-assembly into a variety of nanostructures, with one dimensional (1D) nanostructures being the most easily attainable ones $[1,4]$. The self-assembly process can be promoted and stabilized by several associative interactions, including intermolecular hydrogen bonding, $\pi-\pi$ stacking, hydrophobic collapse, van der Waals, and crystallization. These can be provided from the amino acid side-chains and/or from various chemical segments covalently linked to the peptide backbone. The correlation among the driving forces, chemical moiety, and the type of peptide-based building blocks is summarized in Table 1. As a result of the remarkable structural and functional diversities offered by the various building blocks, peptide-based nanomaterials have broad applications in the area of regenerative medicine [12, 29, 30], drug and gene delivery [20, 31-33], molecular imaging [34], cancer detection [35], cancer therapy [7], antimicrobial agents [36], and immune therapies [37].

In addition to the associative interactions as driving forces, other contributions like electrostatic repulsions [38, 39], elasticity [40], and steric effects [41] can also have an impact on the formation and transformation of these self-assembled supramolecular morphologies. Repulsive and attractive electrostatic interactions can be introduced through charged amino acids and hydrophilic molecules [42]. Electrostatic repulsions tend to cause the disassociation of supramolecular nanostructure into monomeric units while having a limited effect when charged groups are screened by the opposite charges or the electrolytes from the solution. In general, individual peptide molecules first associate into one dimensionally linked tapes (often in the form of $\beta$-sheets) through directional, intermolecular hydrogen bonding. The pitch length of the $\beta$-sheet tapes plays an important role in their lateral stacking, acting in concert with other interactions to define the final assemblies as either finite structures such as fibrils and ribbons or infinite structure such as belts [39]. Electrostatic interactions have a significant effect on the $\beta$-sheet tape's twisting degree and pitch 
length. For example, Mezzenga and coworkers quantified the nano-mechanical properties of various polymorphic forms of amyloid fibrils based on the theory of elasticity [40]. Steric effects always act as an adverse force countering the associative interactions in peptide self-assembly, and influences the degree of molecular packing and stability [41]. Therefore, the final assemblies, including micelles, nanofibers, amyloid fibrils, twist ribbons, helical ribbons, tubes, and belts [4, 42-53], represents the culmination of all the attractive and repulsive interactions, and is a delicate balance between the benefits of aggregation and the detriments of adverse effects. Enzymatic activities and redox reactions can break the balance of associative and repulsive interactions in peptide assemblies by forming new chemical bonds to link several parts together or to cleave off hydrophilic or hydrophobic segments from the parental molecule $[9,35,54-$ 57].

Table 1 The correlations among the associative driving force, chemical moiety and the type of molecular building units.

\begin{tabular}{|c|c|c|c|}
\hline Driving Force & Chemical Moiety & Ref. & Molecular Building Units \\
\hline Hydrogen bonding & Peptide back bone & [58] & All types \\
\hline$\pi-\pi$ Stacking & $\begin{array}{c}\text { Aromatic amino acids } \\
\text { Aromatic segments } \\
\text { Hydrophobic drugs } \\
\text { Nucleobase }\end{array}$ & $\begin{array}{c}{[59]} \\
{[8,54]} \\
{[10]} \\
{[60]} \\
\end{array}$ & $\begin{array}{c}\text { Peptides } \\
\text { Peptide derivatives } \\
\text { Drug amphiphiles } \\
\text { Nucleopeptides } \\
\end{array}$ \\
\hline Hydrophobic collapse & $\begin{array}{l}\text { Alkyl chain } \\
\text { Polymer }\end{array}$ & $\begin{array}{c}{[1,29]} \\
{[61]}\end{array}$ & $\begin{array}{l}\text { Peptide amphiphile and lipopeptide } \\
\text { Peptide-polymer conjugates }\end{array}$ \\
\hline Van der Waals interactions & Polymer & {$[62]$} & Peptide-polymer conjugates \\
\hline Crystallization & $\begin{array}{c}\text { Alkyl chain } \\
\text { Metal complex groups }\end{array}$ & $\begin{array}{c}{[63]} \\
{[64,65]}\end{array}$ & $\begin{array}{l}\text { Peptide amphiphile } \\
\text { Metal complex-peptide conjugates }\end{array}$ \\
\hline
\end{tabular}

\section{Peptide and Peptide Derivatives}

Peptides are ideally suited as stimuli-responsive materials because of the diversity in substituent amino acid functionality and the ability to spontaneously adopt secondary and higher level structures. To promote self-assembly, peptide molecules can be modified using large aromatic groups such as fluorenylmethyloxycarbonyl (Fmoc) and naphthyl $[8,54,66]$. Furthermore, peptides can be specifically degraded by enzymes of a particular type, allowing for the design of enzyme-triggered assembly and disassembly systems. In this section, the term peptide will be used to denote both peptides and peptide derivatives to simplify the description.

Enzymatic condensation of amino acids, hydrolysis, and side chain-modification are the three typical ways to carry out enzyme-instructed self-assembly (EISA) [7, 53, 54], which has attracted extensive research interest in recent years (Figure 2) [22,67]. Proteases that can catalyze the condensation of an amine and a carboxylic acid provide a route for in situ formation of self-assembled peptidic nanostructures from amino acid precursors [68, 69]. When amino acids with aromatic side chains are introduced, supramolecular structures can be generated as a result of electronic modification of the aromatic substituents [70, 71]. Ulijn and coworkers demonstrated that the reversibility of protease-catalyzed condensation can allow the most thermodynamically stable self-assembling nanostructure to dominate a dynamic system. This selection and amplification of the most stable molecular structure could lead to the formation of functional nanostructures with fewer defects [22, 72]. This enzyme-assisted reversible assembly opens up a new avenue to take full advantage of the versatility of peptide design for the discovery of new soft materials. One potential limitation of this approach is that some peptide sequences might not be thermodynamically stable under such conditions, which could lead to difficulties in synthesizing many peptide sequences of interest by protease-catalyzed reaction. To address this shortcoming, Gross and coworkers established a methodology that produced peptides with alternating hydrophilic-hydrophobic 
residues through oligomerization of a lysine-leucine dipeptide [73]. When the protease was added to an aqueous solution of the dipeptide, rapid oligomerization occurred to produce peptides of mixed chain lengths. This mixture underwent a rapid spontaneous sol-gel transition, thereby preventing any further elongation or proteolytic cleavage. The desired structure is thus locked by appropriately tuning the assembling conditions.

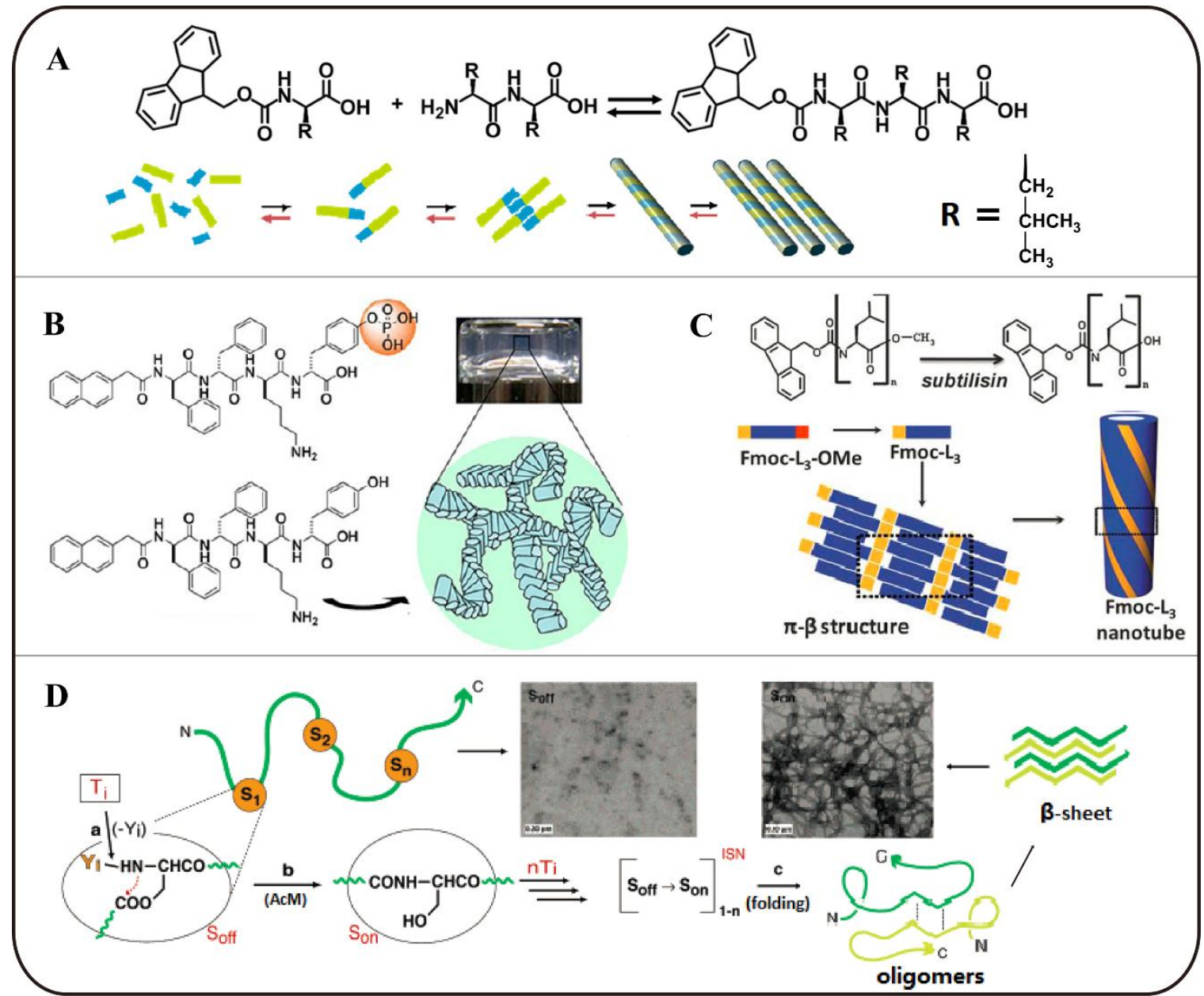

Fig. 2. Examples of enzyme-instructed peptide self-assembly. (A) Protease-catalyzed condensation to yield hydrogelator, which is the thermodynamically stable self-assembling nanostructure. Adapted with permission from Biomaterials, 32, 5304-5310. Copyright 2011 Elsevier Ltd. Enzymatic dephosphorylation (B) and hydrolysis (C) of peptide to form functional supramolecular nanofibers and hydrogels. Adapted with permission from (B) J. Am. Chem. Soc., 135, 9907-9914. Copyright 2013 American Chemical Society. (C) Nanoscale, 2, 960-966. Copyright 2010 The Royal Society of Chemistry. (D) Enzymatic modification on peptide side chain to promote self-assembly and gelation. Adapted with permission from J. Am. Chem. Soc., 127, 11888-11889. Copyright 2013 American Chemical Society.

The self-assembly process can also be induced by enzymatic reactions that facilitate a change in the hydrophobic-hydrophilic balance of the sequence, such as the removal of a solubilizing group. Examples of this include cleavage of an amide bond [74-76], hydrolysis of $C$-terminal methyl ester capped peptides [67, 77, 78], and dephosphorylation of phosphorylated amino acid side chains [79]. Furthermore, modification of peptide side chain functionalities can also promote peptide assembly or gelation. Santos et al. explored this premise, developing a method of an enzymatic switch between the side chain and back bone by in situ intramolecular $O \rightarrow N$ acyl migrations, allowing for the induction of a conformational transition to the $\beta$-sheet secondary structure and spontaneous aggregation [80].

Another interesting application of enzymatic reactions is to design supramolecular peptidic hydrogels with specific degradability in response to a particular protease type [74, 81-83]. In general, self-assembled 
nanostructures, particularly those rich in $\beta$-sheets, prove resistant to proteolytic degradation because the specific cleavage sites are often embedded inside the nanostructures. Accordingly, this issue has led to some rather creative methods that aim to circumvent the embedded cleavage sequence in favor of more accessible sites. For instance, Stupp and co-workers reported peptide nanofibers that could be rapidly disassembled (under 30 mins) to smaller aggregates through the phosphate kinase-mediated phosphorylation of a serine residue. The resulting increase in electrostatic repulsions led to disruption of the $\beta$-sheet within the structure and ultimately to disassembly [84]. This method relies on the observation that there is a relatively high degree of hydration within the nanofibers [85] and that the transformation is occurring on the side-chain functionality, rather than the more hindered peptide backbone. The kinasetriggered release of an encapsulated anticancer drug (doxorubicin) was also demonstrated, suggesting a potential application for this platform. Taking a different approach, Cui and co-workers reported on the rational design of $\beta$-sheet rich supramolecular filaments that can specifically dissociate into less stable micellar assemblies and monomers upon treatment with matrix metalloproteases-2 (MMP-2) [82]. Through linkage of an oligoproline segment to an amyloid-derived peptide sequence, they designed an amphiphilic peptide that can undergo a rapid morphological transition in response to $\mathrm{pH}$ variations. MMP-2 specific peptide substrates were then used as multivalent cross-linkers to covalently fix the amyloid-like filaments in the self-assembled state at $\mathrm{pH} 4.5$. Their results suggested that the cross-linked filaments are stable at $\mathrm{pH}$ 7.5 but gradually break down into much shorter filaments upon cleavage of the peptidic cross-linkers by MMP-2. In contrast, Hartgerink and co-workers used lysyl oxidase (naturally found in serumsupplemented media) to cross-link nanofibers with enhanced mechanical properties, through conversion of the four lysine primary $\varepsilon$-amines to aldehydes and their subsequent condensation with another amine to form imines. Such a process represents a mild, enzyme-mediated method for increasing the mechanical strength of peptide hydrogels and could in the future lead to enzyme-responsive materials [86].

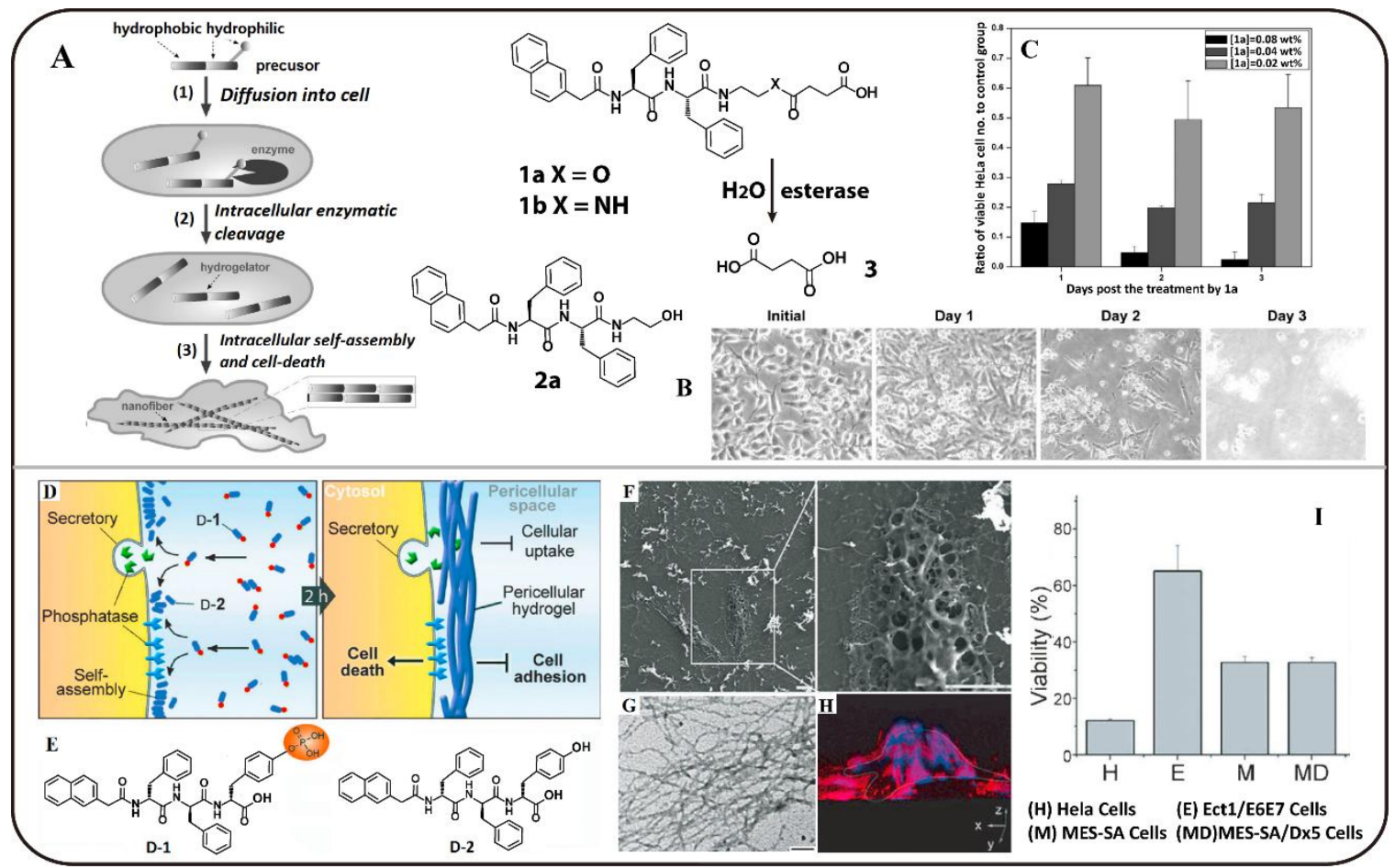

Fig. 3. Enzyme-instructed peptide self-assembly applied in physical cancer therapy. (A) Schematic intracellular formation of hydrogelation inducing cell death. (B) Optical images of HeLa cells after being cultured in the media at different days. The shape change and the decrease of cell number indicated cell death. (C) MTT assays of HeLa cells treated with molecule 1a in (A) at different concentrations. Adapted with permission from Adv. Mater., 19, 3152-3156. Copyright 2007 WILEY-VCH Verlag GmbH \& Co. KGaA, Weinheim. (D) Enzyme-catalyzed formation of pericellular hydrogel/nanonets to induce cell death. (E) Molecular structures of the precursor and the hydrogelator. (F) SEM images of HeLa cells treated with D-1 in (D). (G) TEM images and (H) 3D stacked z-scan images of the pericellular hydrogels on the HeLa cells treated by D-1. (I) Cell viabilities of four cells treated by D-1. Scale bar of (F) (G) is $10 \mu \mathrm{m}$. Adapted with permission from Angew. Chem. Int. Ed., 53, 8104 -8107. Copyright 2014 Wiley-VCH Verlag GmbH \& Co. 
KGaA, Weinheim.

Many of the examples discussed above concern the creation of enzyme-responsive materials that act as structural mimics or as carriers for some bioactive cargo. An interesting deviation from this was provided by $\mathrm{Xu}$ and coworkers, who creatively developed an enzyme-instructed peptide self-assembly platform that could selectively inhibit and even kill multidrug-resistant cancer cells both intracellularly and extracellularly. For intracellular targeting, Xu designed a hydrogelator precursor that was a substrate of carboxylesterase, capable of entering cells through passive diffusion. Once inside the cells, the endogenous carboxylesterase cleaved the solubilizing region of precursor and triggered its assembly into nanofibers. The subsequent increase in viscosity exerted vital stress on the cancer cells, critically impairing cellular function and causing cell death (Figure 3A-C) [87]. For extracellular targeting, a hydrogelator precursor comprised of $D$-amino acids was synthesized. This $D$-peptide exhibited a propensity to form nanostructures in the presence of overexpressed phosphatases from the cancer cells, even at concentrations below the minimum gelation concentration $[88,89]$. However, $D$-peptides are able to significantly resist proteolysis [90], such that little clearance of the hydrogels occurs. The resulting accumulation of the hydrogels creates a blockage in the pericellular space that prevents cellular uptake and mass exchange, ultimately inducing cell apoptosis (Figure 3D-I) [91].

One application that enzyme-catalyzed peptide cleavage and/or disassembly is particularly well suited to is in the design of activatable nanoprobes [35]. The overexpression and abundance of certain proteases in cancers, such as matrix metalloproteases (MMPs) and cathepsins, provide a possible opportunity to identify tumor progression and cancer staging [92]. Edwards and coworkers reported a novel activatable probe using two NIR fluorescent dyes (LS276). The probe is based on a triple-helical peptide substrate that incorporates a native collagen sequence, resulting in the self-assembly of three single-stranded peptides into one triple-helical structure. The collagen sequence has a scissile bond that lies between the amino acids of glycine and valine, and is highly specific for MMP. Upon self-assembly of the triple-helical structure, the three peptide chains intertwine, burying the fluorescent dyes into close proximity and quenching the fluorescence (quenching efficiency up to $85 \%$ ). When the triple-helix is cleaved by the overexpressed MMP from cancer cells, the six short labeled peptide fragments are released, resulting in an amplified fluorescent signal and providing improved in vivo contrast enhancement for sensing tumor tissues (Figure 4A-F) [93].

This idea of using self-assembly to sequester fluorescent reporters was also utilized by Cui and coworkers, who developed a new type of activatable supramolecular nanobeacon [94, 95]. The molecule is composed of three parts: a cell-penetrating Tat peptide derived from HIV that allows effective penetration of the cell membrane; a green fluorescent dye, 5-carboxyfluoroscein (5-FAM), linked to Tat by a peptide linker GFLG (Gly-Phe-Leu-Gly) that can be effectively cleaved by the lysosomal protease, cathepsin B; and a black hole quencher BHQ-1, which possesses a broad absorption profile that enables it to quench the 5-FAM emissions without generating fluorescence of its own. Dissolution of these molecules into aqueous solution results in self-assembly into core-shell micelles that sequester the enzyme-sensitive linker within the micellar core, and gives a greater than $98 \%$ fluorescence quenching efficiency of the dye. Upon accumulating in the acidic tumor microenvironment or entering the lysosomes, the nanobeacons gradually dissociate into individual molecules due to dilution and ionization. The cleavable linker is exposed to the target enzyme and, after cleavage, the free 5-FAM generates significant fluorescence signals. Cui's approach offers an improved signal-to-background contrast that makes it a promising platform for the imaging and diagnosis of cancer cells (Figure 4G-I) [94]. 


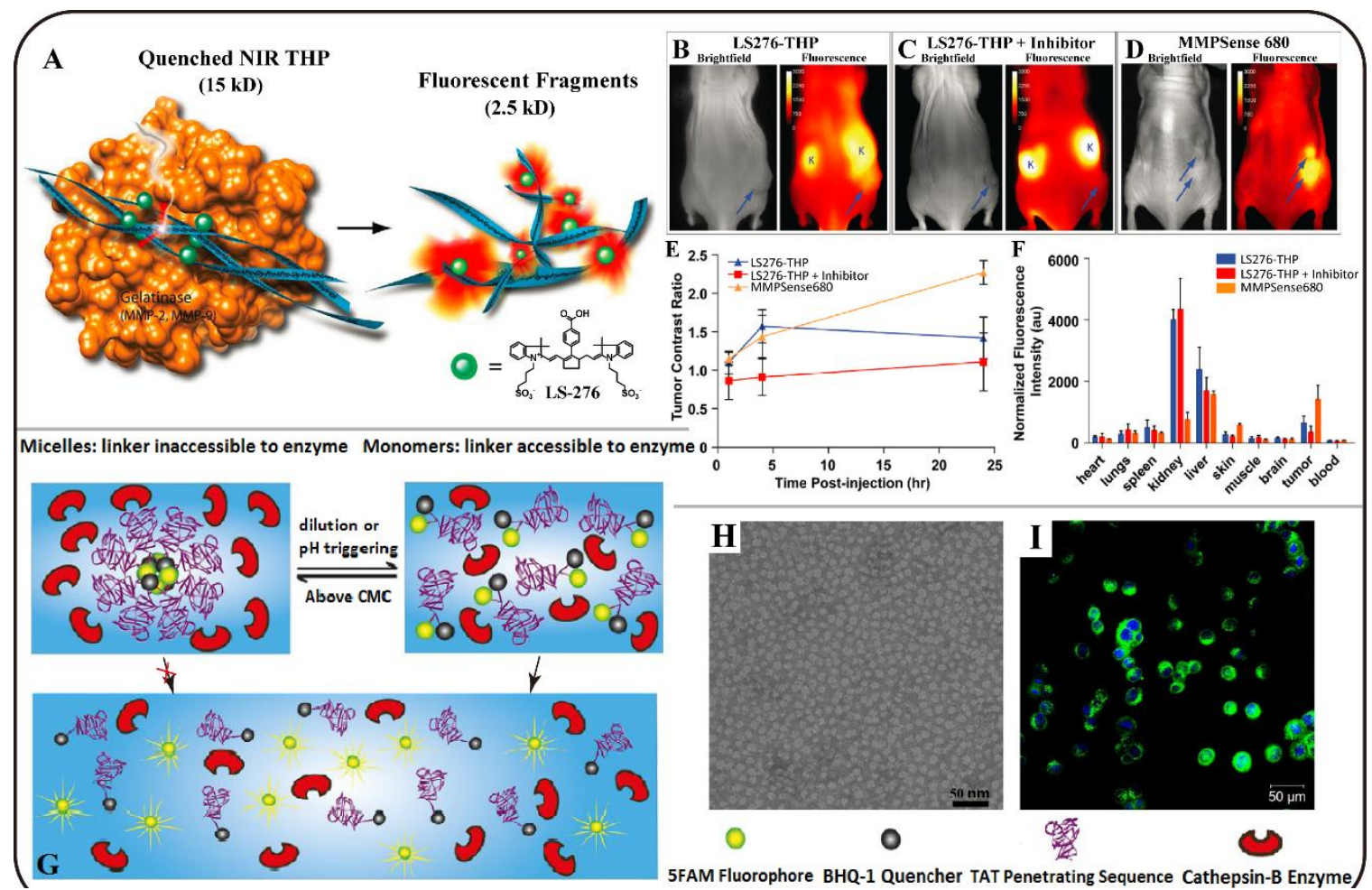

Fig. 4. Enzymatic disassembly of peptide assemblies applied to the design of activatable nanoprobes that target cancer cells. (A) Mechanism of MMP activatable NIR fluorescent probe. (B), (C) and (D) In vivo whole-body images of mice bearing HT1080 tumor xenografts $24 \mathrm{~h}$ after an injection. (E) The ratio of tumor and contralateral thigh ROI fluorescence with respect to time. (F) Fluorescence biodistribution confirmed the high fluorescence in the noninhibited tumors. Adapted with permission from Bioconjugate Chem., 23, 656-663. Copyright 2012 American Chemical Society. (G) Schematic illustration of the expected cleavage and detection mechanism of nanobeacons. (H) TEM images of nanobeacons in PBS solutions reveal self-assembled nanoparticles. (I) Fluorescence images of cells after exposure to nanobeacons. Adapted with permission from ACS Nano, 7, 4924-4932. Copyright 2013 American Chemical Society.

The examples discussed showcase a variety of methods in which enzymatic reactions have been harnessed to control assembly and disassembly of nanostructures and also to trigger the release of bioactive or reporting agents. It is the efficiency and selectivity of enzymes that make them so attractive for this purpose; however, numerous challenges are also evident. The most important is that of access to the cleavable moiety within the nanostructure, if the enzyme cannot interact with this site then no advantage is gained. On the other hand, easy access may lead to premature cleavage by other less selective enzymes that are typically responsible for cellular catabolism. A balance between the two must therefore be achieved, or an alternate pathway found, such as another mechanism that can partially degrade the assembled structure to provide access (a change in $\mathrm{pH}$ for instance). A further issue concerns the effect that the cleavable sequence can have on the assembly itself given that some substrate sequences can contain multiple bulky amino acids that may hinder self-association. However, it is not necessarily simple to predict what the impact would be given the number of different assembly systems reported, and at this time the study is evaluated on a case by case basis.

\section{Peptide-Conjugation Systems}

\subsection{Peptide Amphiphiles}

Peptide amphiphiles (PAs) are a broad class of self-assembling peptide conjugates containing one or more linear hydrocarbons. The Stupp laboratory have designed and synthesized a large body of peptide 
amphiphiles that can assemble in aqueous solution into biologically active one-dimensional (1D) nanofibers $[1,12,30,44]$. A key design feature of Stupp's peptide amphiphiles is the combined use of a $\beta$ sheet forming peptide sequence (often possessing a terminal bioactive epitope) with a long alkyl tail to create an amphiphilic building moiety. The ability of the chosen peptide to form intermolecular hydrogen bonding, acting in concert with the hydrophobic interactions among the alkyl tails, is critical for their assembly into stable 1D structures in aqueous solutions that can further entangle into 3D networks. The resulting hydrogels, with mechanical property, stability and functionality tunable by varying the number and sequences of amino acids, have demonstrated remarkable potential as biologically active scaffolds for regenerative medicine. The self-assembly and disassembly of these PA nanofibers have been designed to respond to a variety of biological triggers [16-18, 84, 96, 97].

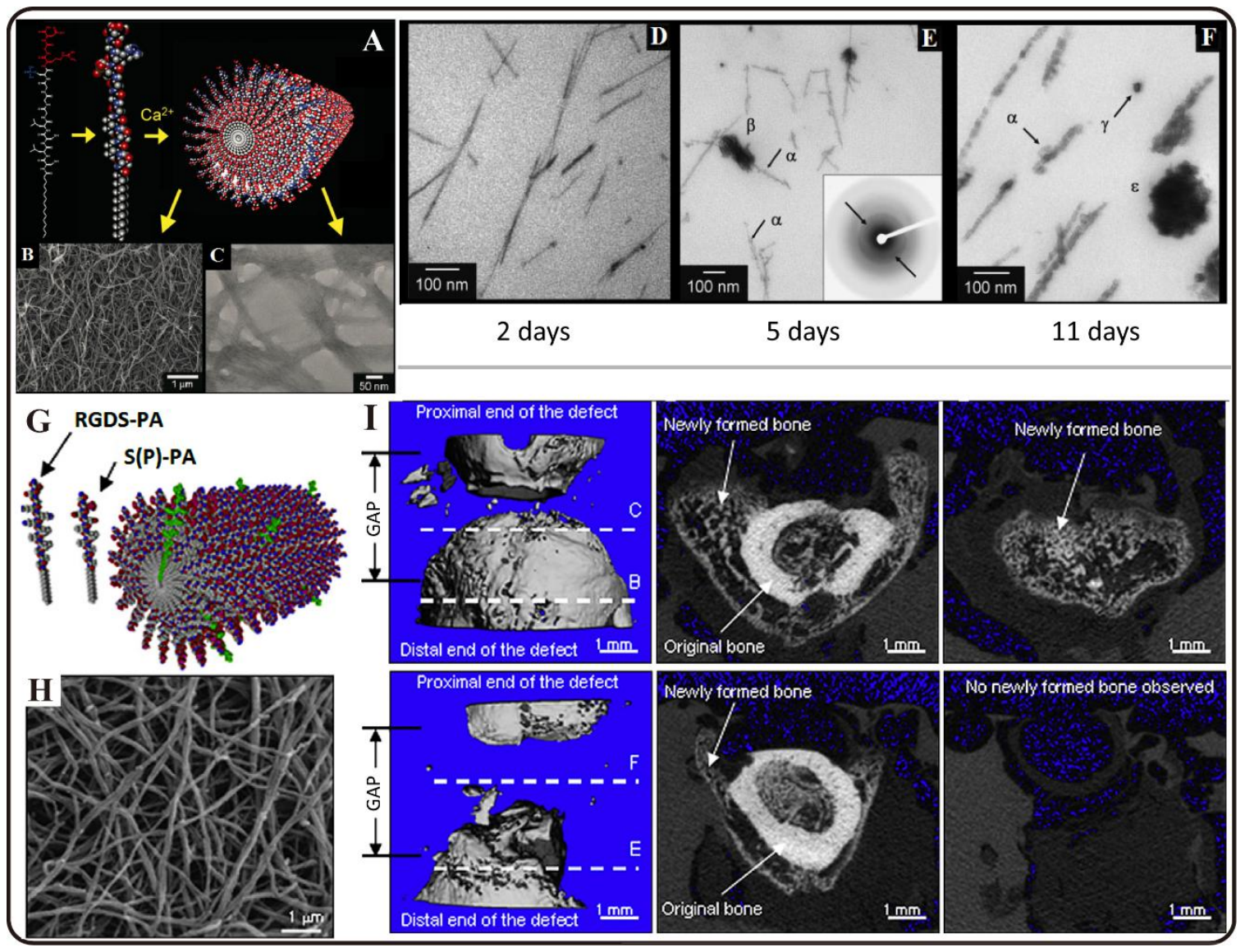

Fig. 5. Enzyme-directed templation of artificial bone mineral in scaffolds comprising peptide amphiphiles designed by the Stupp Laboratory. (A) Schematic illustration of PA assembly into a nanofiber. The scanning electron microscopy (SEM) (B) and TEM micrographs (C) show filamentous nanostructures and fibrous bundles. (D-F)TEM images reveal different stages of mineral evolution of PA nanofibers: nanofibers with calcium phosphate "premineral" after 2 days of mineralization (D); nanofibers with nucleated hydroxyapatite (HA) crystals after 5 days (E) and after 11 days (F). Adapted with permission from Adv. Mater., 21, 425-430. Copyright 2009 WILEY-VCH Verlag GmbH \& Co. KGaA, Weinheim. (G) Schematic illustration of a PA nanofiber formed by co-assembly of PAs containing a terminal phosphorylated serine epitope and PAs containing a terminal RGDS epitope. (H) SEM micrograph of RGDS+S(P)-PA nanofibers. (I) MicroCT imaging of newly formed bone in rats with a critically-sized femoral defect. Representative microCT images depict the difference in bone formation observed in animals implanted with a mixture of RGDScontaining PA and phosphoserine-containing PA in the defect site (up line) versus those left untreated (low line). Adapted with permission from Biomaterials, 31, 6004-6012. Copyright 2010 Elsevier Ltd.

Nanofiber hydrogels formed by PA assembly could structurally and functionally mimic the extracellular matrices (ECMs), providing a synthetic environment for cells to colonize, proliferate, and differentiate. Enzymatic catalysis can be used not only to spatiotemporally construct the hydrogel formation, but also to 
safely break down the networks after their function is fulfilled [16, 84, 97]. For example, Stupp and coworkers designed PAs with phosphorylated serine residues that, when assembled, could present the phosphate groups at the surface for templating bone growth [97]. These surface-displayed phosphate groups offer nucleation centers for calcium ions, allowing two-dimensional mineralization to occur (Figure 5 A-F). After enzymatic catalysis by alkaline phosphatase, hydroxyapatite (HA), an essential component of human's bone tissue, is formed on the nanofiber surface. In another case, two kinds of PAs (one terminates with the RGDS sequence; the other terminates with a phosphoserine residue,) were used to co-assemble into hybrid nanofibers displaying two different types of biological signals [98], with the RGDS epitope recruiting fibronectin and the phosphoserine residues serving as hydroxyapatite nucleation sites (Figure 5 G-I). Four weeks after implantation in an orthotopic rat femoral critical-size defect model, it was found that the biomimetic scaffold significantly promoted the bone regeneration. Higher levels of newly formed bone were observed growing from both ends of the defect tending to bridge the gap and expanding radially outwards. Stupp and coworkers also found that PAs possessing the laminin-1 IKVAV epitope could promote neural progenitor cells to quickly undergo selective and rapid differentiation into neurons [99, 100]. When injected at the site of a spinal cord injury, glial scar formation was significantly reduced both in and around the injury, and both motor and sensory axons were found to have regenerated across the lesion.

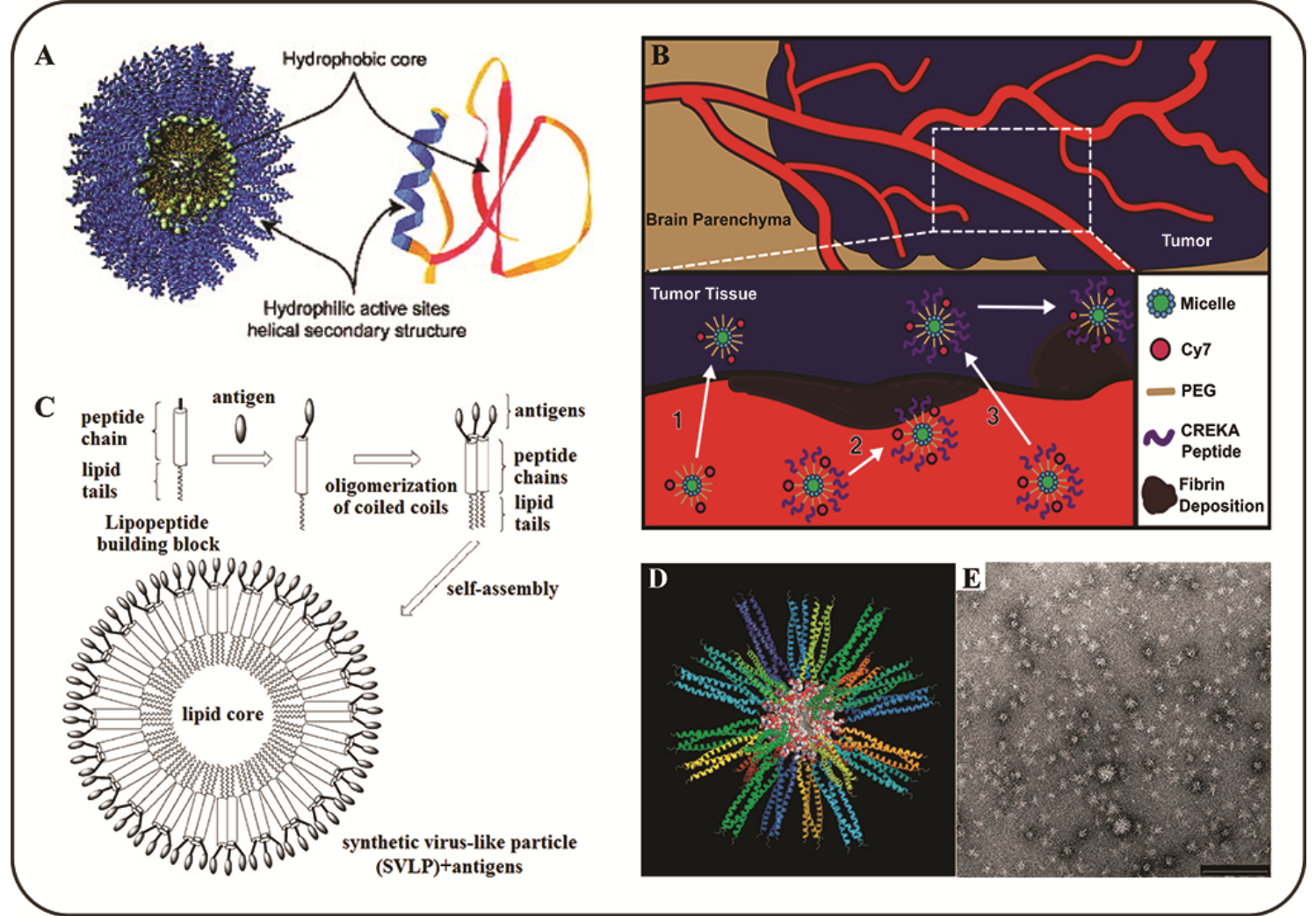

Figure 6 Schematic illustration of protein analogous micelles developed by the Tirrell Laboratory and virus-mimicking micelles. (A) The size and signal display of a protein analogous micelle is very similar to those of a natural protein. Adapted with permission from AIChE Journal, 51, 1249-1256. Copyright 2005 Wiley-VCH Verlag GmbH \& Co. KGaA, Weinheim. (B) Schematic of CREKA decorated PA micelles for targeting glioma via active binding to fibrin. Adapted with permission from Biomaterials, 35, 6004-6012. Copyright 2014 Elsevier Ltd. (C) Illustration of the design and assembly of a synthetic virus-like particle. A proposed model (D) and TEM image (E) of SVLPs formed by selfassembly of the designed lipopeptide in Tris buffer. Scale bar $100 \mathrm{~nm}$. Adapted with permission from Angew. Chem. Int. Ed., 46, 9015-9018. Copyright 2007 Wiley-VCH Verlag GmbH \& Co. KGaA, Weinheim

Tirrell termed the PA assemblies developed in his laboratory as "protein analogous micelles" (Fig. 6A), for their size and biological signal presentation are reminiscent of those of natural proteins $[4,5,101]$. The lipophilic segment drives the designed peptide conjugates to self-assemble into water-soluble micellar structures, with biological signals displaced on the micellar surface. The confinement and tethering of the peptide is important for them to assume a biologically relevant secondary structure. These PA micelles have been explored for treating glioblastoma [102] and atherosclerosis [103-105], and also for nerve 
regeneration[106]. Chuang et al. recently reported the design of glioblastoma-targeting micelles by adding the fibrin-binding pentapeptide (CREKA) to a dye-labeled peptide amphiphile micelles (Figure 6B) [102]. Upon intravenous administration to glioma-bearing mice, these CREKA decorated micelles were found to display enhanced tumor homing via active targeting, as evidenced by in vivo and ex vivo imaging and immunohistochemistry. Histological evaluation revealed no noticeable signs of adverse effects such as cytotoxicity and tissue damages, confirming the safety and utility of the PA system for in vivo applications. Robinson and coworkers created a virus-like particle through self-assembly of an artificial, synthetically derived lipopeptide [107], and demonstrated its use in the stimulation of antigen-specific humoral immune responses (Figure 6C-E)). The basic building block lipopeptide comprises a lipid tail, a coiled-coil peptide sequence and an antigen sequence derived from HIV-1 virus. The coiled-coil motif drove self-assembly of three lipopeptide molecules into a parallel helical bundle. These bundled peptides can further assemble into stable virus-mimicking particles. It was found that displaying multiple copies of antigenic structures on the surface could lead to robust and highly efficient adjuvant-free antigen-specific antibody responses.

\subsection{Drug-Peptide Conjugates}

The covalent linkage of a therapeutic agent with a rationally designed peptide is a strategy that has been developed to create self-assembling drug-peptide conjugates. The bonded drugs such as naproxen [16], paclitaxel [53, 108], camptothecin (CPT) [109], and doxorubicin [110], can spontaneously assemble into various nanostructures under aqueous conditions. Drug amphiphiles (DAs) are a class of small molecule drug-peptide conjugates consisting of a therapeutic agent and a peptide segment [111]. DAs and their selfassembled nanostructures that can provide an effective way to improve the drug's solubility, enhance the drug's targeting efficiency [112], and help circumvent multidrug resistance [113].

From the perspective of systemic delivery for cancer chemotherapy, these self-assembled DA nanostructures are quite stable, as a result of the intermolecular hydrogen bonding among the peptide segment, with possible contributions from $\pi-\pi$ stacking between the aromatic drug. As such, the dissociation occurs only when the solution concentration decreases into nanomolar range. Therefore, the nanostructures will experience little dissociation during circulation [10]. Upon reaching the targeted tumor site, the nanostructure will encounter the required stimulus to trigger their rapid decomposition and the contained drug will be released. Cui and coworkers found that the drug loading of the conjugate could affect the cytotoxicity of the drug amphiphiles (Figure 7). In this study, one, two or four CPT molecules were conjugated to a $\beta$-sheet forming peptide sequence derived from the Tau protein via glutathione (GSH, overexpressed by tumor cells) sensitive linkers, corresponding to fixed drug loadings of $23 \%, 31 \%$, and $38 \%$, respectively. Since the CPT drug must enter the cell nucleus to exert its cytotoxic effect, cellular uptake represents an important step in determining the cytotoxicity of the designed drug conjugates. Due to a balanced hydrophobic-hydrophilic ratio allowing for the most efficient translocation of the conjugate into cells, the molecules with two CPT was found to be the most effective at inhibiting the proliferation of cancer cells [109]. However, the higher loading of the conjugates was also found to affect the stability of the nanostructure, which in turn influenced the sensitivity of the linker toward its triggering stimulus. For the mono-CPT drug amphiphile, the half-life in the presence of GSH was $2 \mathrm{~h}$, whereas for the di- and quadCPT drug amphiphiles it was in excess of $8 \mathrm{~h}$ (Figure 7G). This can be explained by the relative critical aggregation concentrations of the conjugates, with the di- and quad-CPT conjugates having low nanomolar values that are indicative of greater stability when compared to the high nanomolar value of the mono-CPT conjugate. Moreover, it has been shown that using different linker groups to conjugate drugs to peptide backbones [114] or placing the anticancer drug at either of the peptide termini [115] could also have a significant impact on their cytotoxicity against cancer cells. Recently, the Cui lab was able to extend this platform to include more than one therapeutic agent [116], and to obtain other types of supramolecular structures containing a fixed drug loading [117]. 


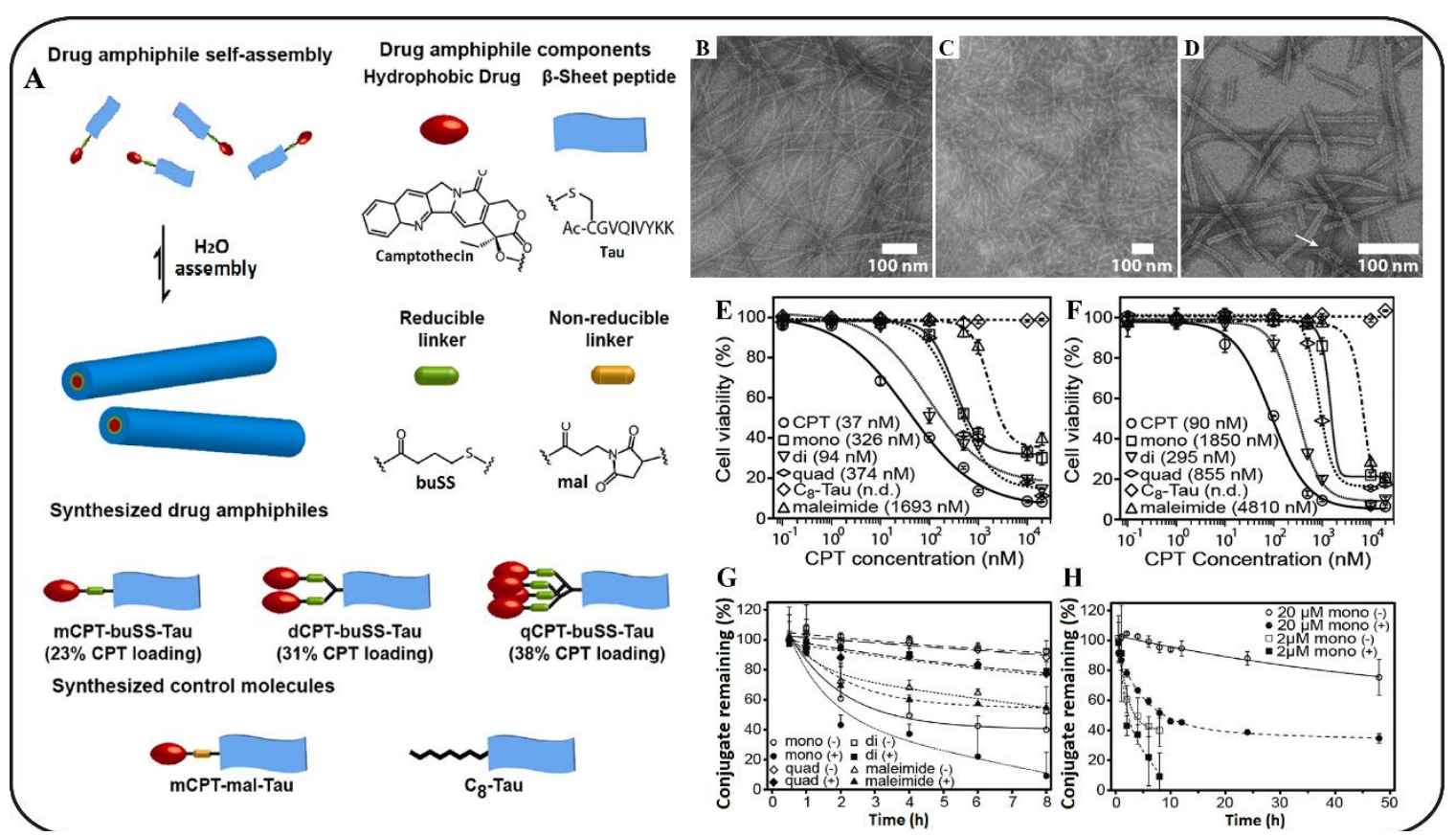

Fig. 7. Examples of redox responsive drug amphiphiles applied in drug delivery. (A) Schematic illustration of the designed and synthesized drug amphiphiles, control molecules, and self-assembled nanostructures. TEM images of nanostructures formed by mCPT-buSS-Tau (B), dCPT-buSS-Tau (C) and qCPT-buSS-Tau (D) in water. Release study of peptide amphihiles and control molecules in the presence and absence of glutathione (GSH) in sodium phosphate (E). Comparison of mCPT-buSS-Tau release kinetics at $2 \mu \mathrm{M}$ and $20 \mu \mathrm{M}(\mathrm{F})$. mono $=$ mCPT-buSS-Tau, di $=\mathrm{dCPT}$-buSSTau, quad = qCPT-buSS-Tau, maleimide $=$ mCPT-mal-Tau, $(+)$ or $(-)$ indicates the presence or absence of glutathione, respectively. In vitro dose-response relationship study of the peptide amphihiles molecules against human MCF-7 breast cancer (G) and rat 9L gliosarcoma (H) cells. Adapted with permission from J. Am. Chem. Soc. 135, 2907-2910. Copyright 2013 American Chemical Society.

Drug-containing hydrogels are useful in various biomedical contexts for the local management of many human diseases such as cancer, and also for treatment of wounds $[6,118]$. An intriguing report by the Xu Lab presented an innovative method for the design of multifunctional supramolecular hydrogels that could serve as potential anti-HIV hydrogels for sustained drug release. They developed a platform in which reverse transcriptase inhibitors where covalently conjugated to peptide molecules via hydrolysable ester bonds. These hydrogel precursors could self-assemble to form a supramolecular hydrogel in weakly acidic conditions upon treatment with prostatic acid phosphatase. The use of $D$-amino acids in the synthesis of the peptide hydrogels not only bestowed a greater biocompatibility on the gel compared with its $L$-amino acid counterpart, but also significantly reduced the rate of gel degradation. Consequently, the anti-HIV drug was released more smoothly and sustainably [119].

\subsection{Nucleopeptides}

Nucleopeptides are novel peptide conjugates containing both nucleobases and amino acids, both of which are important fundamental building blocks in biological systems. Nucleopeptides are regarded as biocompatible materials as those made of peptides, and nucleopeptide hydrogels have been demonstrated to have greater biostability in the presence of proteinase $\mathrm{K}$, a powerful protease that hydrolyzes a wide range of peptides and cleaves peptide bonds adjacent to the carboxyl group of aliphatic and aromatic amino acids with blocked alpha amino groups [60]. To precisely construct a hydrogel at a specific location, enzymatic reactions were introduced and various enzymes explored to modify the nucleopeptide hydrogels in vitro [118] and in vivo [60, 120]. Further expansion of the diversity and applications of these nucleopeptide hydrogelators was accomplished by conjugating another of life's fundamental building blocks - a carbohydrate $[66,121]$. Due to the morphological similarity to extracellular matrices in tissues, the threecomponent peptide hydrogels are biocompatible, biostable and are able to assist single strand nucleic acids 
in entering cells for DNA delivery [121]. Recently, Xu and coworkers showed that the supramolecular assemblies of a small molecule conjugate of nucleobase, amino acids, and saccharide promoted the development of zygotes into blastocysts of mice and the proliferation of murine embryonic stem cells. The assemblies were able to mimic the function of growth factors and bioactive proteins, and might interact with integrins on the cell surface [122].

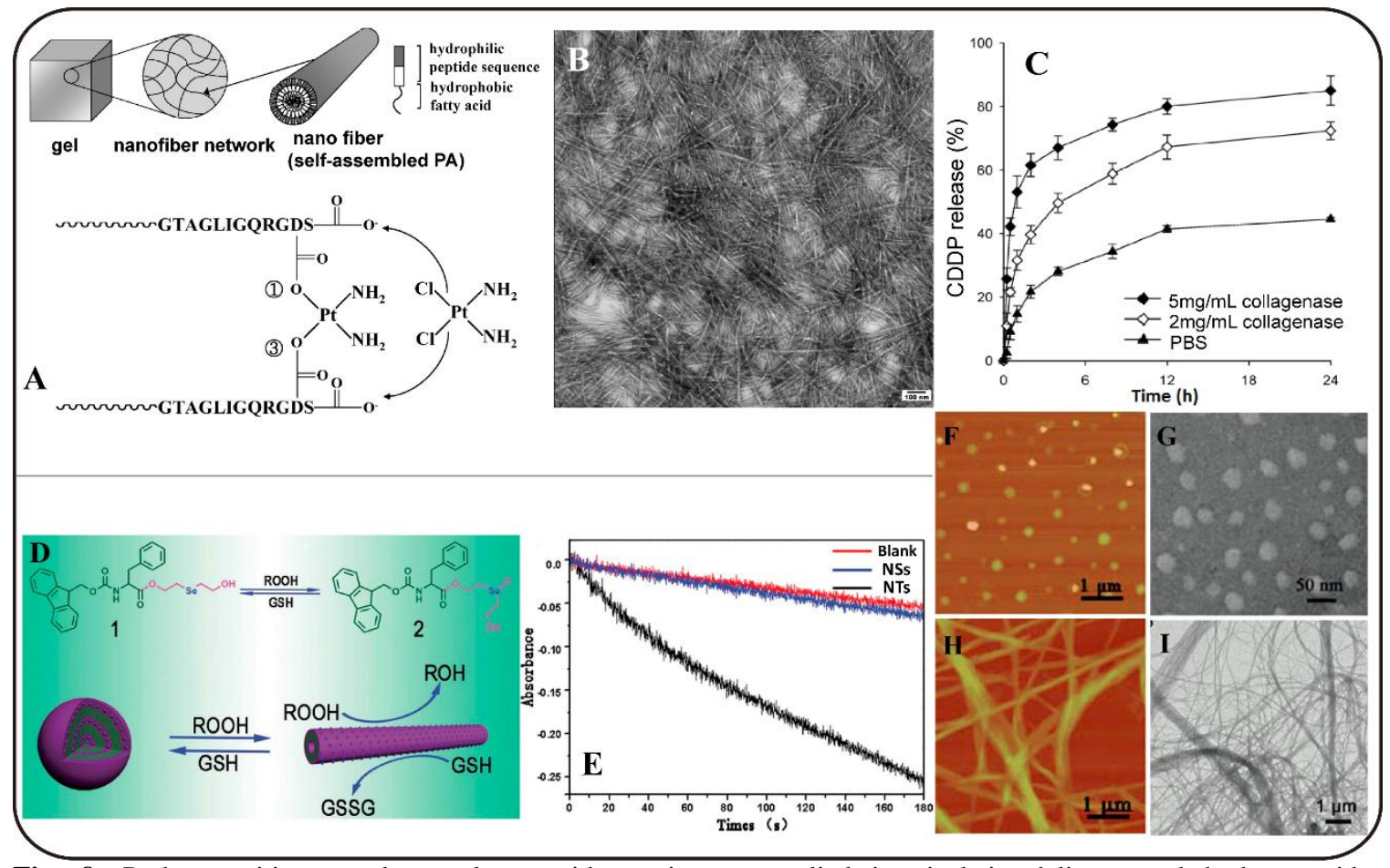

Fig. 8. Redox-sensitive metal complex-peptide conjugates applied in cisplatin delivery and hydroperoxides concentration adjustment. (A) Schematic diagram of a nanofiber-networked gel and presumed mechanism of the interactions between cisplatin and peptide amphiphile. (B) TEM images of nanofiber-networked gels, scale bar $100 \mathrm{~nm}$, [cisplatin]/[peptide]=2. (C) Release profiles of cisplatin at different MMP-2 solution. Adapted with permission Mol. Pharm., 6, 978-985. Copyright 2009 American Chemical Society. (D) Molecular structures of the Se-containing Metal complex-peptide conjugates, and schematic illustration of the redox control of catalytic activity triggered by morphology transformation. (E) Absorbance versus time during the catalytic reduction of ROOH using GSH as reducing substrate AFM and TEM images of the nanospheres self-assembled from compound $\mathbf{1}(\mathrm{F})(\mathrm{G})$, and nanotubes self-assembled from compound 2 (H) (I). Adapted with permission from Soft Matter, 10, 9695-9701. Copyright 2014 The Royal Society of Chemistry.

\subsection{Metal Complex-Peptide Conjugates}

There exists a significant difference in redox potential between the extracellular and intracellular spaces, which is primarily related to the concentration of glutathione inside and outside cells [123, 124]. On this basis, redox-sensitive moieties are attractive in the design of functional stimuli-responsive materials. Metal complex-peptide conjugates have received significant attention due to the variable oxidation states and coordination number of transition-metal ions, which can be exploited to influence the pathway and outcome of redox-induced self-assembly. Metal complex-peptide conjugates act as a receptor for the stimulus and are imparted with versatile properties derived from the metal ion utilized, typically iron, copper, zinc, selenium, or platinum [125-127]. Recently, ferrocene-peptide conjugates were demonstrated to form stable hydrogels in water and organogels in organic solvent (e.g. toluene) [128-130]. The ferrocene group is the redox center that can reversibly control the self-assembly behavior of the peptide conjugate, allowing rapid self-assembly when in its reduced state. Oxidation using $\mathrm{H}_{2} \mathrm{O}_{2}, \mathrm{Ce}^{4+}$, or other oxidizing agents causes the gel to collapse into a liquid state through disruption of the ordered $\beta$-sheet structure. This redox-induced phase transition was found to arise from a morphological transformation between nanofibers and 
nanoparticles, which can be exploited as a switch to control the release of drugs embedded in ferrocenepeptide conjugate hydrogels [64].

In some instances, the metal complex itself can also be the functional element of the biomaterial, a good example being cisplatin (cis-dichlorodiamineplatinum(II), CDDP) which is extensively used as a chemotherapeutic agent for the treatment of different cancers. Thus metal complex-peptide conjugates have a unique advantage for drug delivery. An excellent demonstration of this approach was reported by Kim et al. [127], who developed platinum ( $\mathrm{Pt}$ ) complex-peptide conjugates as a bioresponsive cisplatin delivery system. Comprising a metalloproteinase-2 sensitive peptide, GTAGLIGQRGDS, conjugated to a fatty acid (Figure 8A-C), Pt(II) ions are used to cross-link the peptide molecules by interacting with the carboxylic group of aspartic acid, inducing their supramolecular self-assembly into hydrogels. CDDP release from the hydrogel was triggered by the enzymatic degradation of the MMP-2-sensitive sequence and subsequent ligand exchange with chloride ions, with the release rate dependent on the enzyme concentration. Such hydrogels may provide a spatially and temporally controlled delivery system for targeted anticancer drug delivery.

The variable oxidation state of metal ions within the conjugates can also be harnessed to tune the redox potential of its local environment through redox processes. Liu and coworkers reported a peptide-selenium conjugate as a smart, novel glutathione peroxidase mimic that possesses modulatory catalytic activity based on redox-induced self-assembly that can control the concentration of hydroperoxides (ROOH) (Figure 8D-I) [131]. In its reduced state, the $\mathrm{Se}(\mathrm{II})$-peptide conjugate self-assembles into nanoparticles in aqueous solution, demonstrating extremely low glutathione peroxidase activity. Upon oxidization to Se(IV) by $\mathrm{ROOH}$, the change in the geometry about the Se atom (tetrahedral to trigonal planar) induced a complete morphological transition from nanoparticles into nanotubes, resulting in a great enhancement of the catalytic activity. In the presence of GSH the oxidized selenium is reduced back to the Se(II) state, resulting in the assembly returning to the nanoparticle morphology. The mimic could detect the signal of ROOH and then automatically adjust its activity to achieve "on and off" scavenging of ROOH. This reversible Sebased system can help balance hydroperoxide concentrations in organisms, providing a benefit to the metabolism.

\section{Peptide-Polymer Conjugates}

Peptide-polymer conjugates are a class of soft materials comprising synthetic polymers covalently attached to peptide sequences [132]. Peptide-polymer conjugates have the potential to combine the complementary advantages of peptides and synthetic polymers to generate hybrid materials with complex, enhanced and modular physiochemical properties, and have been widely used in bio-applications [61, 62]. For example, peptides conjugation to polystyrene (PS) and polymaleic acid (HPMA) was demonstrated to enhance permeability and retention, and to promote gelation [133, 134]. Poly(ethylene glycol) (PEG) is the most widely studied polymer, imbuing their conjugates with improved solubility, reduced immunogenicity, increased stability against degradation, increased circulation times, and prolonged biological activity [61, 135, 136]. By introducing bio-responsive moieties [137, 138], peptide-polymer conjugates could be spatiotemporally controlled to form hierarchical supramolecular nanostructures with multiple biofunctions, including drug delivery, gene therapy, and tumor imaging.

For drug delivery, Qi and co-workers [139] developed a docetaxel-loaded nanostructured lipid carrier (DTX-NLC) that was modified with both folate ligands and tumor microenvironment-sensitive polypeptides (TMSP) (Figure 9A-D). Polycationic cell-penetrating peptides (CPP) and folate were both conjugated to distal ends of respective PEG chains. CPPs were incorporated to exploit their penetrating action in overcoming the higher interstitial pressure in the tumor, and the folate ligand allows selective targeting to folate receptor-positive tumors. Both entities provide the ability to enhance specific uptake by cancerous cells and were incorporated onto the surface of a docetaxel-loaded nanostructured lipid carrier. In circulation, the nanoparticles were stable and the penetration capacity was masked by coupling a polyanionic inhibitory peptide to the CPP via a proteinase-sensitive cleavable linker. Upon arrival at the tumor site, the cleavage of the linker was triggered and the cell penetration ability was activated. This dualmodified design takes advantage of the combination of both tumor microenvironment-sensitivity and improved selective drug delivery to cancer cells with reduced intrinsic toxicity to healthy cells. 


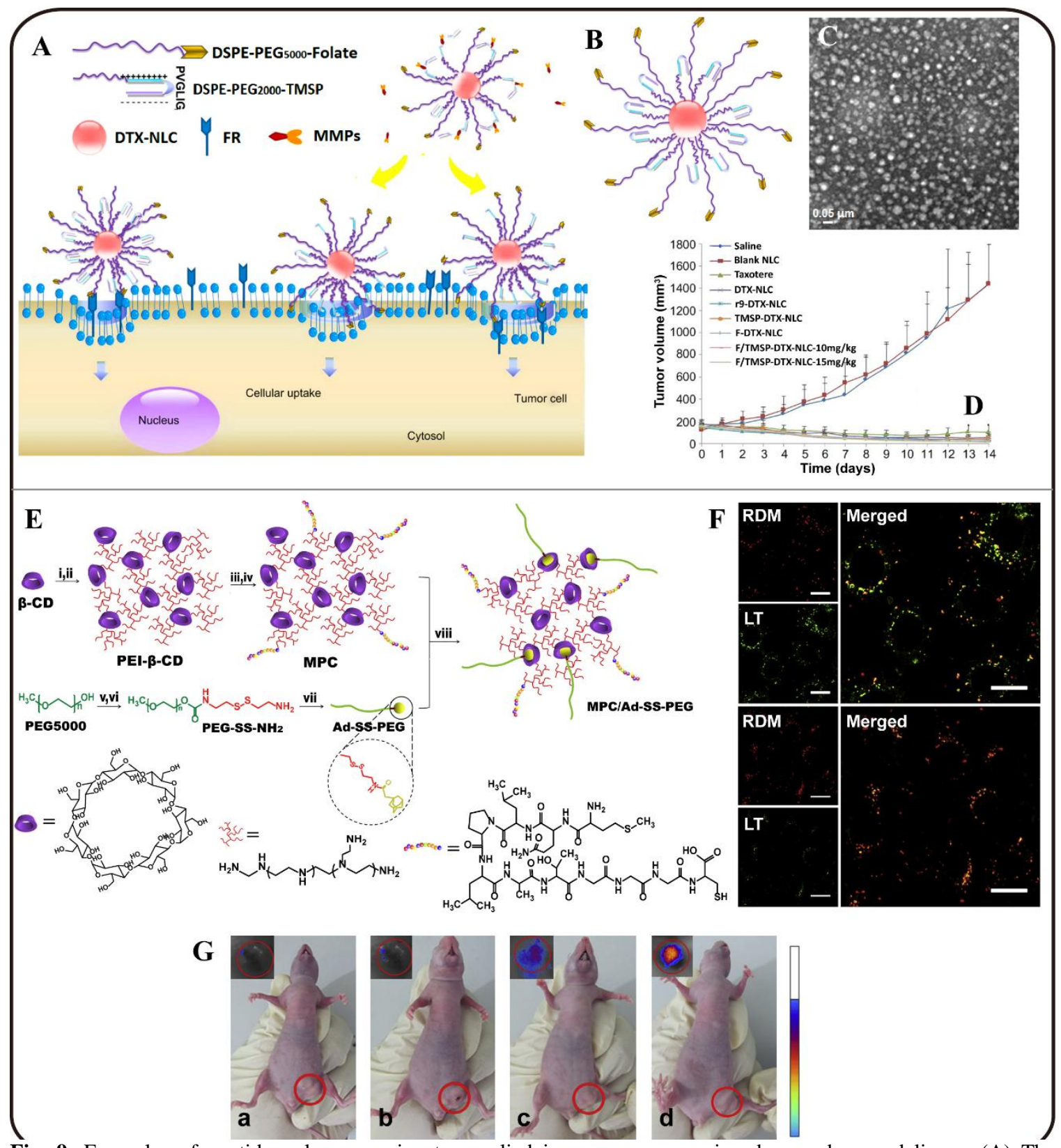

Fig. 9. Examples of peptide-polymer conjugates applied in enzyme responsive drug and gene delivery. (A) The schematic of the multivalent interactions of F/TMSP-DTX-NLC with cancer and (B) schematic of the dual-ligand DTX-NLC modified with folate TMSP . (C) TEM of DTX-NLC. (D) The in vivo antitumor study of docetaxel-loaded NLC in BALB/c mice implanted with KB cells. Adapted with permission Biomaterials 34, 4137-4149. Copyright 2013 Elsevier Ltd. (E) Synthesis route of MPC/Ad-SS-PEG. (F) Intracellular distribution of pDNA (red) mediated by MPC/Ad-SS-PEG polyplexes at the N/P ratio of 25. The plasmid DNA was labeled with red fluorescent rhodamine (RDM) and green fluorescent LysoTracker (LT) was used as late endosome/lysosome marker. The polyplexes were incubated with Hep G2 cells for $6 \mathrm{~h}$ following incubation without polyplexes. The CLSM observation was performed at $6 \mathrm{~h}$ (up) or $12 \mathrm{~h}$ (below) after transfection using $60 \times$ objective. The white scale bar represents $20 \mathrm{~mm}$. (G) Fluorescence images at the tumor site of BALB/C mice $48 \mathrm{~h}$ after the systemic injection of (a) naked DNA, (b) PEI-b$\mathrm{CD} / \mathrm{pEGFP}$ complexes, (c) MPC/pEGFP complexes and (d) MPC/Ad-SS-PEG/pEGFP complexes. Adapted with permission Biomaterials 34, 6482-6494. Copyright 2013 Elsevier Ltd.

For gene therapy, Li and coworkers designed a new redox-sensitive polymer-peptide based gene vector that could specially target fibroblast growth factor receptors (FGFRs) via host-guest supramolecular 
complexation (Figure 9E-G) [140]. The "host" segment contained $\beta$-cyclodextrin combined with lowmolecular-weight polyethylenimine (PEI) and FGFR targeting peptide. The "guest" segment consisted of PEG and an adamantyl group linked by a disulfide bond. After complexation and encapsulation of DNA, the complexes could efficiently condense DNA into nanoparticles around 100-200 nm in diameter. The PEG chains were able to effectively stabilize the DNA polyplexes against salt or BSA induced aggregation, but were readily cleavable intracellularly to induce dissociation and release of the DNA payload. Experiments using different carcinoma cell lines and a tumor-bearing mouse model indicated that complex nanoparticles could mediate significantly higher transfection efficiencies without cytotoxicity and facilitate highly efficient endosomal escape post-transfection. These results demonstrated that complex nanoparticles could be used as a potential safe and efficient non-viral vector for future cancer gene therapy.

Due to their improved stability, longer circulation time and improved tumor targeting properties in vivo, polymer-peptide conjugates can be used as bio-activatable imaging probes in surgery, providing considerable fluorescence contrast to differentiate tumors from normal tissue. Tsien's group developed a peptide-dendrimer conjugate comprising a dendrimer and a fluorescently labeled polycationic cellpenetrating peptide coupled via a cleavable linker to an inhibitory peptide [141]. Upon exposure to proteases in tumorous tissues, the inhibitor was separated from the CPP via cleavage of the linker. The activated probe was then able to bind to and enter tumor cells, delineating the margin between the tumor and adjacent tissues and improving the precision of tumor resection. Furthermore, when the dendrimers were used as nanoparticle cores coated with fluorescent activatable cell penetrating peptides, the accumulation of nanoparticles in tumors was 4 to 15 times higher than those without dendrimers, making it possible to detect residual tumors as small as $200 \mu \mathrm{m}$ [142].

\section{Peptide-Inorganic Hybrid Nanomaterials}

Peptides can also be incorporated onto the surfaces of inorganic material to create peptide-inorganic hybrid nanomaterials, potentially optimizing their comprehensive properties in biological and biomedical applications $[143,144]$. Inorganic nanoparticles are generally robust carriers as they possess low toxicity, good biocompatibility, potential to carry and controlled release of loaded drugs. The grafted peptides can act as intermediate molecules, cancer targeting ligands, or enzyme responsive linkers, imparting selectivity and sensitivity to the hybrid nanomaterials for diagnostic applications. Moreover, the self-assembly of peptide molecules can induce the aggregation and dissociation of the nanoparticles, enhancing the resonance and contrast properties in their use as imaging agents.

The immobilization of the peptide on inorganic nanoparticles is a complex process that is constrained by a large number of factors [143]. Peptides can be linked to nanoparticles either by chemical covalent bonds or by physical adsorption (van der Waals, electrostatic and hydrophobic interactions). The extent of surface accumulation is determined by the nature of the peptide molecules (including the peptide sequence, molecular configuration and conformation) [145], the physicochemical properties of the nanoparticle surface, and characteristics of the adsorption process (solution $\mathrm{pH}$, ionic strength, temperature) [146]. The most widely used inorganic nanoparticles in bio-applications are magnetic particles, gold particles, and silica particles due to their appropriate sizing, capacity for peptide adsorption, and biocompatibility for tumor detection [147-149] and drug delivery [150] applications.

Magnetic resonance imaging (MRI) is a frequently used noninvasive imaging technique for tumor detection that affords a high spatial resolution without the need for ionizing radiation. However, MRI suffers from limited sensitivity and image contrast, and magnetic particles that are commonly utilized as contrast agents lack the specificity to target tumor cells. To increase the specificity of these contrast agents, Weissleder and coworkers described peptide-magnetic hybrid nanoparticles as magnetic relaxation switches [151]. The peptide substrates consisted of a central sequence with a protease recognition and cleavage site, with biotin ligand conjugated at each terminal. This dual biotinylated peptide acted as a cross-linker by interacting with magnetic nanoparticles whose surfaces were modified with avidin, thereby inducing aggregation. The clustered nanoparticles presented a higher spin-spin relaxation time $\left(T_{2}\right)$ from the surrounding water. After cleavage of the peptide cross-linkers by proteases from tumor cells, the nanoparticles aggregates dissociated with a concomitant reduction in $T_{2}$. On the other hand, to increase the image contrast, Long and coworkers developed two sets of iron oxide magnetic nanoparticles with biorthogonal azide and alkyne surfaces, respectively, to offer a high spatial resolution MRI signal (Figure 
10A-D). The reactive moieties of these magnetic nanoparticles (MNP) were masked by CXCR4 targeted peptide-PEG conjugate layers using matrix metalloproteinase enzyme-sensitive peptide linkers. Upon arriving at the tumor site the linker was degraded, unmasking the MNPs that then underwent copper-free click conjugation between the azide and alkyne surface groups. The resulting self-assembled superparamagnetic nanocluster network exhibited a $160 \%$ enhancement in the $T_{2}$ signal [152].

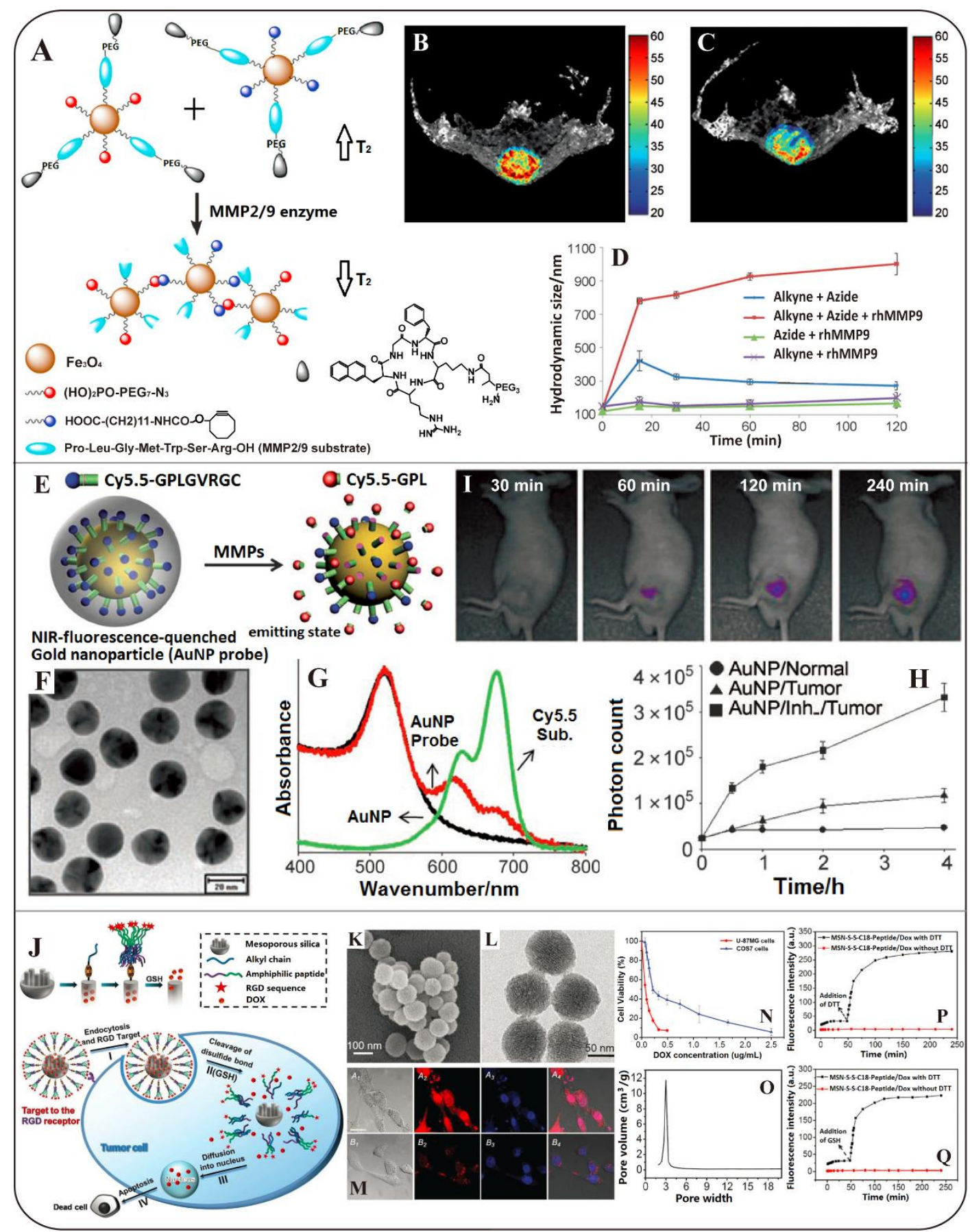

Fig. 10. Examples of peptide-inorganic hybrid nanomaterials applied in imaging and drug delivery. (A) In vitro and in vivo "clicking" NPs. Two iron oxide nanoparticles were designed to undergo a bioorthogonal reaction after cleavage by MMP, which exposes the azide or alkyne moieties on either set of NPs. Representative tumor T2 maps managed from a series of spin echo images with different TEs before (B) and $4 \mathrm{~h}$ after the injection of NPs (C). Bar scale is milliseconds. (D) Hydrodynamic size measurement of the magnetic NPs with/without rhMMP9. Adapted with permission Angew. 
Chem. Int. Ed., 53, 9550-9554. Copyright The Authors. Published by Wiley-VCH Verlag GmbH \& Co. KGaA, Weinheim. (E) The MMP-sensitive AuNP probe. (F) TEM image of the AuNP probe. (G) UV/Vis spectra of AuNP, AuNP-probe, and Cy5.5-substrate solutions. $(\mathrm{H})$ Quantitative image analysis performed by counting the total number of photons in tumors. (I) NIRF tomographic images of subcutaneous-SCC7-tumor-bearing mice after injection of the AuNP probe with inhibitor. Adapted with permission from Angew. Chem. Int. Ed., 47, 2804-2807. Copyright 2008 Wiley-VCH Verlag GmbH \& Co. KGaA, Weinheim. (J) Schematic structure of redox-responsive mesoporous silica nanoparticles (RRMSN/DOX) and redox-responsive cancer targeting drug delivery: I) cell uptake through RGD mediated interaction; II) glutathione-triggered drug release via cleavage of disulfide bond; III) drug diffusing into cytoplasm and eventually to the nucleus; IV) apoptosis of cancer cells. (K) SEM and TEM (L) image of MSNs. (M) Confocal laser scanning microscopy images of U-87 MG (up) and COS7 cells (down) treated with RRMSN/DOX for 4 h. (N) Viability of U-87 MG and COS7 cells after incubated by RRMSN/DOX. (O) Pore size distribution in MSN. Release profile of the drug from RRMSN/DOX at $\mathrm{pH} 7.4$ with/without DTT (P), GSH (Q). Adapted with permission Nanoscale, 7, 10071-10077. Copyright The Royal Society of Chemistry 2015.

One important bio-application of gold nanoparticles is as an imaging probe. Gold colloids possess a plasmon band with a high molar absorptivity and exhibit a color change (a red-shift in the visible spectrum) on transitioning from an aggregated state to fully dispersed solution [153, 154]. Laromaine et al. utilized this phenomenon to develop a peptide-gold hybrid nanoparticle platform. The peptide domain, with a protease cleavable section and an $N$-terminal Fmoc group, was anchored onto the gold surface through a cysteine thiol group. In solution, the terminal Fmoc groups promote physical assembly through $\pi-\pi$ stacking interactions, resulting in aggregation of multiple hybrid nanoparticles. Upon enzymatic hydrolysis of the cleavable peptide, disassembly occurred through a combination of electrostatic repulsions between particle-bound $\mathrm{NH}_{3}{ }^{+}$groups and removal of the hydrophobic interactions between Fmoc groups. Consequently, the solution color changes to indicate with high sensitivity the presence of over-expressed proteases from the tumor [154]. On the other hand, the application of conventional fluorescent probes is limited due to insufficient or limited resolution. The limited degree of resolution is mainly attributed to the low fluorescence-quenching efficiency. Biocompatible gold nanoparticles offer an advantage in obtaining optical images through their strong quenching properties in the near-infrared- region of the spectrum [155, 156]. Gold nanoparticles can experience strong electronic interactions with chromophores in close proximity, with the donation of excited electrons to the gold particles giving almost perfect quenching of the fluorescence. By adding a MMP-sensitive peptide on the particle surface, the quenched probes will be activated by enzyme-catalyzed hydrolysis at the tumor site. Thus the designed peptide-gold nanoparticles can perform with a high quenching efficiency and specific recognition properties, both of which are essential for the development of supersensitive fluorescence-based probes (Figure 10E-H) [148].

Mesoporous silica nanoparticles (MSN) have been intensively applied for controlled drug and gene release, owing to their large surface area, tunable pore size, and good biocompatibility. Xiao et al. [150] developed a redox-responsive drug nanocarrier by noncovalently immobilizing the amphiphilic peptides containing the RGD ligand on the MSN surface (Figure 10J-Q). They first anchored a cysteine-functionalized stearic acid (C18) to the surface of a doxorubicin-loaded MSN via disulfide bond formation. Next, the peptide C18-DSDSDSDSRGDS was self-assembled on the particle surface through hydrophobic interactions with the anchored octadecyl groups, forming a coating around the particle to prevent the drug from leaking out. In vitro experiments showed that internalization of the modified MSNs into cancer cells occurs via receptor mediated endocytosis, after which the disulfide bond is cleaved by GSH to remove surface amphiphilic peptides and alkyl chains and induce a considerably rapid drug release. Peptide-silica hybrid nanoparticles as a drug delivery system provide a novel, facile, and effective strategy for the development of smart and targeted drug carriers for cancer therapy

\section{Conclusions and future perspective}

In this work, we reviewed various types of peptide-based nanomaterials that are designed to be responsive to enzymatic or redox reactions, so as to enable supramolecular assembly, disassembly, degradation, and morphological transformations. In the presence of specific stimuli, the states of the materials (e.g. assembly, disassembly and immolation) could be spatiotemporally controlled, facilitating their use in a wider context of biomedical applications, such as regenerative medicine, drug delivery, immunotherapies, and cancer therapeutics. The dimension and morphology of the resultant nanostructure is

be eventually determined by the competing and cooperative intermolecular and intramolecular forces, 
which is a function of the assembly condition and can also be altered by enzymatic or redox reactions.

There are however, many challenges ahead in improving these systems for translation into clinical usage. First, the specificity of the stimulus-triggered reactions should be further improved. Since peptides made of natural amide acids are completely biodegradable, there always exists non-specific degradation by some undesired enzymatic reactions. One possible solution is to develop new screening methodologies to identify peptide sequences with the highest possible $K_{c a} / K_{M}$ value to the enzyme of interest. At the same time, caution must be taken when adding auxiliary or biologically relevant segments to the identified peptide in order to minimize the steric, electronic, or other possible effects that could reduce the binding specificity. The impact of self-assembly on the enzymatic or redox reactions should also be taken into consideration, which may shield the binding site from being accessed by the target stimulus. Second, targeted delivery of peptidic materials to the desired sites should be further improved. The stimulus-triggered reactions are expected to take place only in particular sites, ranging from specific organs, tissues, cell types, to extracellular or intracellular environments; however, these stimulating agents could be present elsewhere, possibly at different concentrations. At the current stage, target delivery of molecules, nanostructures, or materials is a subject of intensive research in the community of drug delivery. The complexity of in vivo environment and the disease-dependent pathological conditions complicate the design of peptide-systems for specific targeting. Third, it is lack of effective control over the reaction kinetics and pathways. The enzymatic or redox reaction separates the studied system into two or more distinct states, however, the timescale and pathways of converting from one state to another could have many possibilities, particularly in the presence of many bio-factors that could potentially co-assemble with the peptidic molecules. Lastly, it is still a challenge to construct peptide assembling system that could be sequentially responsive to multiple types of stimuli in a highly regulated manner. Cells use a cascade of extracellular and intracellular activities for signal transduction to regulate biological events. In contrast, peptide-based assembly systems reported so far are mostly responsive to one kind of enzyme or reducing/oxidizing agent. Multiple responsive systems are rare, and could be an interesting area of research worth of pursuing. Although many challenges ahead, we believe that the current status of peptide-based supramolecular nanomaterials points to a highly promising future in which greater control over their function can be achieved and harnessed for better clinical diagnostics and treatments.

\section{Acknowledgments}

We are grateful for support provided by the National Science Foundation (DMR/1255281, DMR/1506937, and CHE/1412985).

\section{References}

[1] H.G. Cui, M.J. Webber, S.I. Stupp, Biopolymers, 94 (2010) 1-18.

[2] S.I. Stupp, R.H. Zha, L.C. Palmer, H.G. Cui, R. Bitton, Faraday Discuss., 166 (2013) 9-30.

[3] S.I. Stupp, L.C. Palmer, Chemistry of Materials, 26 (2014) 507-518.

[4] A. Trent, R. Marullo, B. Lin, M. Black, M. Tirrell, Soft Matter, 7 (2011) 9572-9582.

[5] R.S. Tu, M. Tirrell, Adv. Drug Deliv. Rev., 56 (2004) 1537-1563.

[6] F. Zhao, M.L. Ma, B. Xu, Chem. Soc. Rev., 38 (2009) 883-891.

[7] J. Zhou, B. Xu, Bioconjug. Chem., 26 (2015) 987-999.

[8] S. Fleming, R.V. Ulijn, Chem. Soc. Rev., 43 (2014) 8150-8177.

[9] M. Zelzer, S.J. Todd, A.R. Hirst, T.O. McDonald, R.V. Ulijn, Biomater. Sci., 1 (2013) 11-39.

[10] R. Lin, H.G. Cui, Curr. Opin. Chem. Eng., 7 (2015) 75-83.

[11] H.G. Cui, V. Krikorian, J. Thompson, A.P. Nowak, T.J. Deming, D.J. Pochan, Macromolecules, 38 (2005)

7371-7377.

[12] J. Boekhoven, S.I. Stupp, Adv. Mater., 26 (2014) 1642-1659.

[13] J. Hardy, D.J. Selkoe, Science, 297 (2002) 353-356.

[14] I. Usov, J. Adamcik, R. Mezzenga, ACS Nano, 7 (2013) 10465-10474.

[15] F. Chiti, C.M. Dobson, Annu. Rev. Biochem., 75 (2006) 333-366. 
[16] M. Conda-Sheridan, S.S. Lee, A.T. Preslar, S.I. Stupp, Chem. Commun., 50 (2014) 13757-13760.

[17] T. Muraoka, C.Y. Koh, H.G. Cui, S.I. Stupp, Angew. Chem. Int. Ed., 48 (2009) 5946-5949.

[18] S. Sur, J.B. Matson, M.J. Webber, C.J. Newcomb, S.I. Stupp, Acs Nano, 6 (2012) 10776-10785.

[19] R.J. Mart, R.D. Osborne, M.M. Stevens, R.V. Ulijn, Soft Matter, 2 (2006) 822-835.

[20] S. Aluri, S.M. Janib, J.A. Mackay, Adv. Drug. Deliv. Rev., 61 (2009) 940-952.

[21] C.G. Pappas, P.W. Frederix, T. Mutasa, S. Fleming, Y.M. Abul-Haija, S.M. Kelly, A. Gachagan, D. Kalafatovic, J. Trevino, R.V. Ulijn, S. Bai, Chem. Commun. (Camb), 51 (2015) 8465-8468.

[22] R.J. Williams, A.M. Smith, R. Collins, N. Hodson, A.K. Das, R.V. Ulijn, Nat. Nanotechnol., 4 (2009) 19-24.

[23] J.P. Schneider, D.J. Pochan, B. Ozbas, K. Rajagopal, L. Pakstis, J. Kretsinger, J. Am. Chem. Soc., 124 (2002) 15030-15037.

[24] L.A. Haines, K. Rajagopal, B. Ozbas, D.A. Salick, D.J. Pochan, J.P. Schneider, J. Am. Chem. Soc., 127 (2005) 17025-17029.

[25] Y. Hu, P. Zhang, R. Lin, J. Fern, A.G. Cheetham, K. Patel, R. Schulman, C. Kan, H. Cui, ACS nano, 10 (2016) 880-888.

[26] W. Li, F. Nicol, F.C.J. Szoka, Adv. Drug Deliv. Rev., 56 (2004) 967-985.

[27] K. Chockalingam, M. Blenner, S. Banta, Protein Eng. Des. Sel., 20 (2007) 155-161.

[28] D.W. Lowik, E.H. Leunissen, M. van den Heuvel, M.B. Hansen, J.C. van Hest, Chem. Soc. Rev., 39 (2010) 3394-3412.

[29] J.B. Matson, S.I. Stupp, Chem. Commun. (Camb), 48 (2012) 26-33.

[30] J.B. Matson, R.H. Zha, S.I. Stupp, Curr. Opin. Solid State Mater. Sci., 15 (2011) 225-235.

[31] P.C. Zhang, A.G. Cheetham, Y.A. Lin, H. Cui, ACS Nano, 7 (2013) 5965-5977.

[32] H. Su, J.M. Koo, H.G. Cui, J. Control. Release, 219 (2015) 383-395.

[33] M. Raad, E.A. Teunissen, E. Mastrobattista, Nanomedicine (Lond), 9 (2014) 2217-2232.

[34] K.E. Bullok, S.T. Gammon, S. Violini, A.M. Prantner, V.M. Villalobos, V. Sharma, D. Piwnica-Worms, Mol Imaging, 5 (2006) 1-15.

[35] P. Zhang, A.G. Cheetham, L.L. Lock, Y. Li, H. Cui, Curr. Opin. Biotechnol., 34C (2015) 171-179.

[36] A. Dehsorkhi, V. Castelletto, I.W. Hamley, J Pept. Sci., 20 (2014) 453-467.

[37] I.W. Hamley, Chem. Commun., 51 (2015) 8574-8583.

[38] A. Aggeli, M. Bell, L.M. Carrick, C.W.G. Fishwick, R. Harding, P.J. Mawer, S.E. Radford, A.E. Strong, N. Boden, J. Am. Chem. Soc., 125 (2003) 9619-9628.

[39] A. Aggeli, I.A. Nyrkova, M. Bell, R. Harding, L. Carrick, T.C.B. McLeish, A.N. Semenov, N. Boden, Proc. Natl. Acad. Sci. U. S. A., 98 (2001) 11857-11862.

[40] I. Usov, R. Mezzenga, Acs Nano, 8 (2014) 11035-11041.

[41] J.A. Hodges, R.T. Raines, J. Am. Chem. Soc., 127 (2005) 15923-15932.

[42] Y. Kuang, Y. Gao, J. Shi, J. Li, B. Xu, Chem Commun (Camb), 50 (2014) 2772-2774.

[43] T. Shimada, S. Lee, F.S. Bates, A. Hotta, M. Tirrell, J Phys Chem B, 113 (2009) 13711-13714.

[44] J.D. Hartgerink, E. Beniash, S.I. Stupp, Proc. Natl. Acad. Sci. U. S. A., 99 (2002) 5133-5138.

[45] S.R. Diegelmann, N. Hartman, N. Markovic, J.D. Tovar, J. Am. Chem. Soc., 134 (2012) 2028-2031.

[46] T. Eichner, S.E. Radford, Mol. Cell, 43 (2011) 8-18.

[47] R.V. Ulijn, A.M. Smith, Chem. Soc. Rev., 37 (2008) 664-675.

[48] E.T. Pashuck, S.I. Stupp, J. Am. Chem. Soc., 132 (2010) 8819-8821.

[49] C.W.G. Fishwick, A.J. Beevers, L.M. Carrick, C.D. Whitehouse, A. Aggeli, N. Boden, Nano Lett., 3 (2003)

1475-1479.

[50] S.G. Zhang, Nat. Biotechn., 21 (2003) 1171-1178.

[51] H. Cui, T. Muraoka, A.G. Cheetham, S.I. Stupp, Nano Lett., 9 (2009) 945-951.

[52] T.J. Moyer, H.G. Cui, S.I. Stupp, J. Phys. Chem. B, 117 (2013) 4604-4610.

[53] Y. Gao, Y. Kuang, Z.F. Guo, Z. Guo, I.J. Krauss, B. Xu, J. Am. Chem. Soc., 131 (2009) 13576-13577.

[54] Y. Gao, Z. Yang, Y. Kuang, M.L. Ma, J. Li, F. Zhao, B. Xu, Biopolymers, 94 (2010) 19-31.

[55] W.J. King, W.L. Murphy, Polym. Chem., 2 (2011) 476-491.

[56] J. Leckie, A. Hope, M. Hughes, S. Debnath, S. Fleming, A.W. Wark, R.V. Ulijn, M.D. Haw, ACS Nano, 8 (2014) 9580-9589.

[57] S.K.M. Nalluri, C. Berdugo, N. Javid, P. Frederix, R.V. Ulijn, Angew. Chem. Int. Ed., 53 (2014) 58825887. 
[58] J.D. Hartgerink, E.R. Zubarev, S.I. Stupp, Curr. Opin. Solid State Mater. Sci., 5 (2001) 355-361.

[59] M. Reches, E. Gazit, Science, 300 (2003) 625-627.

[60] X. Li, Y. Kuang, H.C. Lin, Y. Gao, J. Shi, B. Xu, Angew. Chem. Int. Ed., 50 (2011) 9365-9369.

[61] O.D. Krishna, K.L. Kiick, Biopolymers, 94 (2010) 32-48.

[62] J.Y. Shu, B. Panganiban, T. Xu, Annu. Rev. Phys. Chem., 64 (2013) 631-657.

[63] J.D. Hartgerink, E. Beniash, S.I. Stupp, Science, 294 (2001) 1684-1688.

[64] Z. Sun, Z. Li, Y. He, R. Shen, L. Deng, M. Yang, Y. Liang, Y. Zhang, J. Am. Chem. Soc., 135 (2013) 1337913386.

[65] H.B. Kraatz, J. Lusztyk, G.D. Enright, Inorg. Chem., 36 (1997) 2400-2405.

[66] D. Wu, J. Zhou, J. Shi, X. Du, B. Xu, Chem. Commun., 50 (2014) 1992-1994.

[67] A.K. Das, R. Collins, R.V. Ulijn, Small, 4 (2008) 279-287.

[68] M. Hughes, H.X. Xu, P.W.J.M. Frederix, A.M. Smith, N.T. Hunt, T. Tuttle, I.A. Kinloch, R.V. Ulijn, Soft Matter, 7 (2011) 10032-10038.

[69] R.J. Williams, T.E. Hall, V. Glattauer, J. White, P.J. Pasic, A.B. Sorensen, L. Waddington, K.M. McLean, P.D. Currie, P.G. Hartley, Biomaterials, 32 (2011) 5304-5310.

[70] C.G. Pappas, Y.M. Abul-Haija, A. Flack, P.W. Frederix, R.V. Ulijn, Chem. Commun., 50 (2014) 1063010633.

[71] S. Debnath, S. Roy, R.V. Ulijn, J. Am. Chem. Soc., 135 (2013) 16789-16792.

[72] A.K. Das, A.R. Hirsth, R.V. Ulijn, Faraday Discuss., 143 (2009) 293-303; discussion 359-272.

[73] X. Qin, W. Xie, S. Tian, J. Cai, H. Yuan, Z. Yu, G.L. Butterfoss, A.C. Khuong, R.A. Gross, Chem. Commun. (Camb), 49 (2013) 4839-4841.

[74] K.M. Galler, L. Aulisa, K.R. Regan, R.N. D'Souza, J.D. Hartgerink, J. Am. Chem. Soc., 132 (2010) 32173223.

[75] D. Kalafatovic, M. Nobis, N. Javid, P.W.J.M. Frederix, K.I. Anderson, B.R. Saunders, R.V. Ulijn, Biomater. Sci., 3 (2015) 246-249.

[76] Y. Chau, Y. Luo, A.C. Cheung, Y. Nagai, S. Zhang, J.B. Kobler, S.M. Zeitels, R. Langer, Biomaterials, 29 (2008) 1713-1719.

[77] A.R. Hirst, S. Roy, M. Arora, A.K. Das, N. Hodson, P. Murray, S. Marshall, N. Javid, J. Sefcik, J. Boekhoven, J.H. van Esch, S. Santabarbara, N.T. Hunt, R.V. Ulijn, Nat. Chem., 2 (2010) 1089-1094.

[78] H.X. Xu, A.K. Das, M. Horie, M.S. Shaik, A.M. Smith, Y. Luo, X.F. Lu, R. Collins, S.Y. Liem, A.M. Song, P.L.A. Popelier, M.L. Turner, P. Xiao, I.A. Kinloch, R.V. Ulijn, Nanoscale, 2 (2010) 960-966.

[79] J. Gao, W. Zheng, D. Kong, Z. Yang, Soft Matter, 7 (2011) 10443.

[80] S. Dos Santos, A. Chandravarkar, B. Mandal, R. Mimna, K. Murat, L. Saucede, P. Tella, G. Tuchscherer, M. Mutter, J. Am. Chem. Soc., 127 (2005) 11888-11889.

[81] M.C. Giano, D.J. Pochan, J.P. Schneider, Biomaterials, 32 (2011) 6471-6477.

[82] Y.A. Lin, Y.C. Ou, A.G. Cheetham, H.G. Cui, Biomacromolecules, 15 (2014) 1419-1427.

[83] D. Yuan, J.F. Shi, X.W. Du, N. Zhou, B. Xu, J. Am. Chem. Soc., 137 (2015) 10092-10095.

[84] M.J. Webber, C.J. Newcomb, R. Bitton, S.I. Stupp, Soft Matter, 7 (2011) 9665-9672.

[85] J.D. Tovar, R.C. Claussen, S.I. Stupp, J. Am. Chem. Soc., 127 (2005) 7337-7345.

[86] E.L. Bakota, L. Aulisa, K.M. Galler, J.D. Hartgerink, Biomacromolecules, 12 (2011) 82-87.

[87] Z.M. Yang, K.M. Xu, Z.F. Guo, Z.H. Guo, B. Xu, Adv. Mater., 19 (2007) 3152-+.

[88] J. Shi, X. Du, D. Yuan, J. Zhou, N. Zhou, Y. Huang, B. Xu, Biomacromolecules, 15 (2014) 3559-3568.

[89] J. Zhou, X. Du, Y. Gao, J. Shi, B. Xu, J. Am. Chem. Soc., 136 (2014) 2970-2973.

[90] J. Li, Y. Gao, Y. Kuang, J. Shi, X. Du, J. Zhou, H. Wang, Z. Yang, B. Xu, J. Am. Chem. Soc., 135 (2013) 9907-9914.

[91] Y. Kuang, J. Shi, J. Li, D. Yuan, K.A. Alberti, Q. Xu, B. Xu, Angew. Chem. Int. Ed., 53 (2014) 8104-8107.

[92] E.S. Olson, T.A. Aguilera, T. Jiang, L.G. Ellies, Q.T. Nguyen, E.H. Wong, L.A. Gross, R.Y. Tsien, Integr. Biol. (Camb), 1 (2009) 382-393.

[93] W.J. Akers, B. Xu, H. Lee, G.P. Sudlow, G.B. Fields, S. Achilefu, W.B. Edwards, Bioconjug. Chem., 23 (2012) 656-663.

[94] L.L. Lock, A.G. Cheetham, P. Zhang, H. Cui, ACS Nano, 7 (2013) 4924-4932.

[95] L.L. Lock, Z. Tang, D. Keith, C. Reyes, H.G. Cui, ACS Macro Lett., 4 (2015) 552-555.

[96] T.J. Moyer, J.A. Finbloom, F. Chen, D.J. Toft, V.L. Cryns, S.I. Stupp, J. Am. Chem. Soc., 136 (2014) 
14746-14752.

[97] E.D. Spoerke, S.G. Anthony, S.I. Stupp, Adv. Mater., 21 (2009) 425-+.

[98] A. Mata, Y.B. Geng, K.J. Henrikson, C. Aparicio, S.R. Stock, R.L. Satcher, S.I. Stupp, Biomaterials, 31 (2010) 6004-6012.

[99] G.A. Silva, C. Czeisler, K.L. Niece, E. Beniash, D.A. Harrington, J.A. Kessler, S.I. Stupp, Science, 303 (2004) 1352-1355.

[100] V.M. Tysseling, V. Sahni, E.T. Pashuck, D. Birch, A. Hebert, C. Czeisler, S.I. Stupp, J.A. Kessler, J. Neurosci. Res., 88 (2010) 3161-3170.

[101] M. Tirrell, AIChE J., 51 (2005) 2386-2390.

[102] E.J. Chung, Y. Cheng, R. Morshed, K. Nord, Y. Han, M.L. Wegscheid, B. Auffinger, D.A. Wainwright, M.S. Lesniak, M.V. Tirrell, Biomaterials, 35 (2014) 1249-1256.

[103] D. Peters, M. Kastantin, V.R. Kotamraju, P.P. Karmali, K. Gujraty, M. Tirrell, E. Ruoslahti, Proc. Natl. Acad. Sci. U. S. A., 106 (2009) 9815-9819.

[104] E.J. Chung, L.B. Mlinar, K. Nord, M.J. Sugimoto, E. Wonder, F.J. Alenghat, Y. Fang, M. Tirrell, Adv. Healthcare Mater., 4 (2015).

[105] E.J. Chung, M. Tirrell, Adv. Healthcare Mater., 4 (2015) 2408-2422.

[106] K.A. Black, B.F. Lin, E.A. Wonder, S.S. Desai, E.J. Chung, B.D. Ulery, R.S. Katari, M.V. Tirrell, Tissue Eng. Part A, 21 (2015) 1333-1342.

[107] F. Boato, R.M. Thomas, A. Ghasparian, A. Freund-Renard, K. Moehle, J.A. Robinson, Angew. Chem. Int. Ed., 46 (2007) 9015-9018.

[108] R. Lin, A.G. Cheetham, P. Zhang, Y.A. Lin, H. Cui, Chem. Commun., 49 (2013) 4968-4970.

[109] A.G. Cheetham, P. Zhang, Y.A. Lin, L.L. Lock, H. Cui, J. Am. Chem. Soc., 135 (2013) 2907-2910.

[110] Z. Chen, P. Zhang, A.G. Cheetham, J.H. Moon, J.W. Moxley, Jr., Y.A. Lin, H. Cui, J. Control. Release., 191 (2014) 123-130.

[111] H. Su, J.M. Koo, H.G. Cui, J. Control. Release, 219 (2015) 383-395.

[112] E.L. Sievers, M. Linenberger, Curr. Opin. Oncol., 13 (2001) 522-527.

[113] E.A. Dubikovskaya, S.H. Thorne, T.H. Pillow, C.H. Contag, P.A. Wender, Proc. Natl. Acad. Sci. U.S.A., 105 (2008) 12128-12133.

[114] A.G. Cheetham, Y.C. Ou, P. Zhang, H. Cui, Chem. Commun., 50 (2014) 6039-6042.

[115] P. Zhang, A.G. Cheetham, L.L. Lock, H. Cui, Bioconjugate Chem., 24 (2013) 604-613.

[116] A.G. Cheetham, P. Zhang, Y.A. Lin, R. Lin, H. Cui, J. Mater. Chem. B, 2 (2014) 7316-7326.

[117] Y.A. Lin, A.G. Cheetham, P.C. Zhang, Y.C. Ou, Y.G. Li, G.S. Liu, D. Hermida-Merino, I.W. Hamley, H.G. Cui, ACS Nano, 8 (2014) 12690-12700.

[118] D. Wu, X. Du, J. Shi, J. Zhou, N. Zhou, B. Xu, J. Colloid Interface Sci., 447 (2015) 269-272.

[119] J. Li, X. Li, Y. Kuang, Y. Gao, X. Du, J. Shi, B. Xu, Adv. Healthcare Mater., 2 (2013) 1586-1590.

[120] D. Yuan, R. Zhou, J. Shi, X. Du, X. Li, B. Xu, RSC Adv., 4 (2014) 26487-26490.

[121] X. Li, Y. Kuang, J. Shi, Y. Gao, H.C. Lin, B. Xu, J. Am. Chem. Soc., 133 (2011) 17513-17518.

[122] X. Du, J. Zhou, O. Guvench, F.O. Sangiorgi, X. Li, N. Zhou, B. Xu, Bioconjugate Chem., 25 (2014) 10311035.

[123] E. Fleige, M.A. Quadir, R. Haag, Adv. Drug Deliv. Rev., 64 (2012) 866-884.

[124] F.Q. Schafer, G.R. Buettner, Free Radic. Biol. Med., 30 (2001) 1191-1212.

[125] P. Faller, C. Hureau, O. Berthoumieu, Inorg. Chem., 52 (2013) 12193-12206.

[126] X. Miao, W. Cao, W. Zheng, J. Wang, X. Zhang, J. Gao, C. Yang, D. Kong, H. Xu, L. Wang, Z. Yang, Angew. Chem. Int. Ed., 52 (2013) 7781-7785.

[127] J.K. Kim, J. Anderson, H.W. Jun, M.A. Repka, S. Jo, Mol. Pharm., 6 (2009) 978-985.

[128] B. Adhikari, H.B. Kraatz, Chem. Commun., 50 (2014) 5551-5553.

[129] B. Adhikari, R. Afrasiabi, H.-B. Kraatz, Organometallics, 32 (2013) 5899-5905.

[130] Y. Wang, R. Huang, W. Qi, Z. Wu, R. Su, Z. He, Nanotechnology, 24 (2013) 465603.

[131] Z. Huang, Q. Luo, S. Guan, J. Gao, Y. Wang, B. Zhang, L. Wang, J. Xu, Z. Dong, J. Liu, Soft Matter, 10 (2014) 9695-9701.

[132] A. Carlsen, S. Lecommandoux, Curr. Opin. Colloid Interfac. Sci., 14 (2009) 329-339.

[133] H. Maeda, T. Matsumoto, T. Konno, K. Iwai, M. Ueda, J. Protein Chem., 3 (1984) 181-193.

[134] W. Yuan, J. Yang, P. Kopeckova, J. Kopecek, J. Am. Chem. Soc., 130 (2008) 15760-15761. 
[135] F.M. Veronese, G. Pasut, Drug Discov. Today, 10 (2005) 1451-1458.

[136] H. Otsuka, Y. Nagasaki, K. Kataoka, Adv. Drug Deliv. Rev., 55 (2003) 403-419.

[137] D. Bacinello, E. Garanger, D. Taton, K.C. Tam, S. Lecommandoux, Eur. Polym. J., 62 (2015) 363-373.

[138] T. Koga, K. Kitamura, N. Higashi, Chem. Commun., (2006) 4897-4899.

[139] W. Gao, B. Xiang, T.T. Meng, F. Liu, X.R. Qi, Biomaterials, 34 (2013) 4137-4149.

[140] Y. Ping, Q. Hu, G. Tang, J. Li, Biomaterials, 34 (2013) 6482-6494.

[141] Q.T. Nguyen, E.S. Olson, T.A. Aguilera, T. Jiang, M. Scadeng, L.G. Ellies, R.Y. Tsien, Proc. Natl. Acad. Sci. U.S.A. 107 (2010) 4317-4322.

[142] E.S. Olson, T. Jiang, T.A. Aguilera, Q.T. Nguyen, L.G. Ellies, M. Scadeng, R.Y. Tsien, Proc. Natl. Acad. Sci. U.S.A., 107 (2010) 4311-4316.

[143] D. Aili, M.M. Stevens, Chem. Soc. Rev., 39 (2010) 3358-3370.

[144] A. Vallee, V. Humblot, C.M. Pradier, Acc. Chem. Res., 43 (2010) 1297-1306.

[145] K. Nakanishi, T. Sakiyama, K. Imamura, J. Biosci. Bioeng., 91 (2001) 233-244.

[146] A.E. Nel, L. Madler, D. Velegol, T. Xia, E.M. Hoek, P. Somasundaran, F. Klaessig, V. Castranova, M. Thompson, Nat. Mater., 8 (2009) 543-557.

[147] D. Hogemann, V. Ntziachristos, L. Josephson, R. Weissleder, Bioconjugate Chem., 13 (2002) 116-121.

[148] S. Lee, E.J. Cha, K. Park, S.Y. Lee, J.K. Hong, I.C. Sun, S.Y. Kim, K. Choi, I.C. Kwon, K. Kim, C.H. Ahn, Angew. Chem. Int. Ed., 47 (2008) 2804-2807.

[149] X. Du, J. Zhou, L. Wu, S. Sun, B. Xu, Bioconjugate Chem., 25 (2014) 2129-2133.

[150] D. Xiao, H.Z. Jia, N. Ma, R.X. Zhuo, X.Z. Zhang, Nanoscale, 7 (2015) 10071-10077.

[151] M. Zhao, L. Josephson, Y. Tang, R. Weissleder, Angew. Chem. Int. Ed., 42 (2003) 1375-1378.

[152] J. Gallo, N. Kamaly, I. Lavdas, E. Stevens, Q.D. Nguyen, M. Wylezinska-Arridge, E.O. Aboagye, N.J. Long, Angew. Chem. Int. Ed., 53 (2014) 9550-9554.

[153] C. Guarise, L. Pasquato, V. De Filippis, P. Scrimin, Proc. Natl. Acad. Sci. U.S.A., 103 (2006) 3978-3982. [154] A. Laromaine, L. Koh, M. Murugesan, R.V. Ulijn, M.M. Stevens, J. Am. Chem. Soc., 129 (2007) 41564157.

[155] E.E. Connor, J. Mwamuka, A. Gole, C.J. Murphy, M.D. Wyatt, Small, 1 (2005) 325-327.

[156] C.S. Yun, A. Javier, T. Jennings, M. Fisher, S. Hira, S. Peterson, B. Hopkins, N.O. Reich, G.F. Strouse, J. Am. Chem. Soc., 127 (2005) 3115-3119. 